\title{
Dual Language Profiles in Spanish-Speaking English Learners
}

Pumpki Lei Su${ }^{1}$, Raúl Rojas ${ }^{2}$, and Aquiles Iglesias ${ }^{1}$

$9{ }^{1}$ Department of Communication Sciences and Disorders, College of Health Sciences, University of Delaware, Newark, Delaware, 19713

$11{ }^{2}$ Department of Speech, Language, and Hearing, University of Texas at Dallas, Richardson, Texas, 75080

Author Note

16 PUBLISHED IN THE JOURNAL OF SPEECH, LANGUAGE, AND HEARING

\section{RESEARCH.}

18

19 The authors do not have any known or potential conflicts of interest.

21 Correspondence concerning this article should be addressed to Pumpki Lei Su, Department of

22 Communication Sciences and Disorders, College of Health Sciences, University of Delaware,

23100 Discovery Blvd, Newark, DE 19713. Email: pls@udel.edu 


\section{Abstract}

25 Purpose: The purpose of this study was to identify and describe latent dual language profiles in

26 a large sample of school-aged Spanish-English bilingual children designated as English Learners

27 (ELs) by their school district.

28 Method: Data for this study include 847 Spanish-speaking ELs from kindergarten to third grade.

29 Spanish and English narrative retell language samples were collected from all participants. Four

30 oral language measures were calculated in Spanish and English, including the subordination

31 index (SI), moving average type-token ratio (MATTR), Narrative Structure Scheme (NSS), and

32 words per minute (WPM) using Systematic Analysis of Language Transcript (SALT). These

33 indicator measures were used in a latent profile analysis to identify dual language profiles.

34 Results: The optimal model represents a four-profile solution, including a Spanish-dominant

35 group (average Spanish, low English), an English-dominant group (low Spanish, average

36 English), and two balanced groups (a balanced-average group and a balanced-high group).

37 Additionally, participants displayed uneven performance across language domains and distinct

38 patterns of unique strength or weakness in a specific domain in one of their two languages.

39 Conclusions: Findings from this study highlight the large variability in English and Spanish oral

40 language abilities in school-aged Spanish-speaking ELs and suggest that a dichotomous

41 classification of ELs vs English-proficient students may not be sufficient to determine the type of

42 educational program that best fits a specific bilingual child's need. These findings highlight the

43 need to assess both languages across multiple language domains to paint a representative picture

44 of a bilingual child's language abilities. The dual language profiles identified may be used to

45 guide the educational program selection process to improve the congruence among the linguistic

46 needs of an individual child, teachers' use of instructional language, and the goals of the 
47 educational program (i.e., improving English proficiency vs. supporting dual language

48 development). 


\section{Dual Language Profiles in Spanish-Speaking English Learners}

The number of families in the United States who speak a language other than English has

51 tripled in the last several decades (Espinosa, 2015). It is estimated that over 40 million

52 individuals in the US speak Spanish at home (U.S. Census Bureau, 2015). Although many

53 children raised in these Spanish-speaking families will eventually speak English and become

54 proficient bilingual users, a large proportion of these children will enter school with "limited

55 English proficiency," a descriptive term used by the U.S. Department of Education. These

56 children are often designated as English Learners (ELs) and placed in a variety of educational

57 programs designed to instruct the requisite English skills to eventually demonstrate grade-

58 appropriate academic achievement in English. The specific educational program placement is

59 largely determined by program availability and parental choice. Outcome studies that have

60 examined the effectiveness of educational programs for linguistic minority students have found

61 contradictory patterns, which have been attributed to the differences in the specific sample

62 studied and methodologies used across studies (Slavin \& Cheung, 2005). Rarely has the research

63 community questioned whether the divergent outcomes of the studies are influenced by the

64 potential dual language profiles of the children receiving a particular model of instructions.

65 Identifying and describing dual language profiles would facilitate the placement of educational

66 programs for ELs so that the instructional language aligns with specific types of students'

67 linguistic skills and strengths. The purpose of the present study is to identify and describe distinct

68 dual language profiles (i.e., systematic linguistic differences that distinguish one subgroup of

69 children from another) among Spanish-English bilingual children who have been designated as

70 ELs by public school districts upon school entry.

71 Rationale for the Potential Presence of Distinct Dual Language Profiles 
Much attention has been given to the growth of English skills in Spanish-speaking ELs,

73 which is not surprising given that the major goal across educational programs for ELs has been

74 to improve children's oral and literacy skills in English. Significantly less studied are the Spanish

75 proficiency and the potential presence of distinct dual language profiles in these children. The

76 proficiency level in the first language is rarely formally assessed during the educational program

77 placement process for ELs (Boyle et al., 2015). Additionally, even though the notion that

78 bilingual children are not a linguistically homogenous group is no longer a new idea (Cummins

79 \& Mulcahy, 1978; Gutiérrez-Clellen, 1999; Hoff \& Core, 2015), it is still common for

80 practitioners to consider and treat these children as a homogenous group using a monolithic

81 instructional approach.

82 However, there is clear rationale for the potential presence of distinct dual language

83 profiles. Previous studies have found a considerable range of linguistic skills across various

84 domains even among monolingual children (Conti-Ramsden et al., 1997; Tomblin \& Zhang,

85 2006). The variability in linguistic skills is likely magnified for bilingual children ${ }^{1}$ compared to $^{-1}$

86 monolingual children because we would expect three sources of variability, including normal

87 individual variability in linguistic skills across children, variability in individual children's

88 exposure to the two languages, and the potential interaction between the two languages. There

89 are two interrelated components that contribute to the variability in bilingual children's exposure

90 to their two languages. One component is the onset of exposure to the second language. Some

91 children, referred to as simultaneous bilinguals, are exposed to two languages either from birth or

92 shortly after (Genesee et al., 2004; Hoff et al., 2012). Other children, referred to as sequential or

\footnotetext{
${ }^{1}$ Throughout this manuscript, we use the term "bilingual children" to refer to children who are exposed to and are learning two languages. We use English Learners (ELs) to refer to a subset of bilingual children who have been designated as ELs by their school district.
} 
93 successive bilinguals, are first exposed to one language and have made progress towards its

94 acquisition when they begin learning a second language (Genesee et al., 2004). A second

95 component that introduces additional complexity is the amount (i.e., quantity) and the type (i.e.,

96 quality) of language exposure in each language, which varies considerably within and across

97 various groups of children acquiring two languages (De Houwer, 2007). Although simultaneous

98 bilinguals have extensive and continuous exposure to both languages from an early age, the

99 quantity and the quality of their exposure to each language is not always equivalent (Genesee et

100 al., 1995; Unsworth, 2016). For sequential bilinguals, the onset, quantity, and quality of exposure

101 to each language are variable across individual children. For both types of bilinguals, their level

102 of performance in each language will vary as a function of their exposure to each language.

103 Theoretically, children categorized as ELs in the school system could be either simultaneous or

104 sequential bilinguals. Regardless of the specific type of bilingual an EL student is, the interaction

105 between the onset of language exposure and the quantity and quality of input results in a myriad

106 of linguistic possibilities amongst ELs. Lastly, there may be various degrees of interaction

107 between the two languages depending on the specific languages a bilingual child is learning

108 (Paradis \& Genesee, 1996; Serratrice, 2013). Bilingual children learning two languages with

109 great typological proximity were found to have better vocabulary compared to bilingual children

110 learning two languages that are distant from each other (Blom et al., 2020; Floccia et al., 2018).

111 In summary, by the time these children enter school, it is reasonable to hypothesize that they will

112 have a variety of skills in each language as a function of their individual linguistic experience.

\section{Importance of Identifying Distinct Dual Language Profiles}

114 Identifying dual language profiles within Spanish-speaking ELs carries both practical and

115 clinical significance. Hispanic children are the largest and fastest growing bilingual population in 
116 the US and those designated as ELs show considerably lower levels of school achievement than

117 their non-EL peers (García et al., 2011; Hernandez et al., 2008; Klingner et al., 2012). Spanish-

118 speaking ELs have the highest high school dropout rate relative to any other group, with $31 \%$

119 failing to complete high school, compared to 10\% in monolingual English-speaking peers (U.S.

120 Department of Education, 2006). Given language skills highly predict later achievement

121 outcomes in ELs (Hoff, 2013; Kieffer, 2012), more research that seeks to understand this

122 population to better meet their linguistic needs in educational programs are critically needed to

123 address the well-documented achievement gap between Spanish-speaking ELs and their

124 monolingual English-speaking peers.

125 A variety of educational programs designed to improve student outcomes and close

126 achievement gaps for Spanish-speaking ELs are available. The specific definition of educational

127 programs for ELs varies across states and districts. Generally, these programs can be

128 characterized as programs that focus on either developing students' oral and literate proficiency

129 in two languages (e.g., Dual Language) or English proficiency whether that be from the onset of

130 schooling (Structured English Immersion) or a gradual shift from the heritage language to

131 English academic instruction (Transitional Bilingual) (Boyle et al., 2015; Office of English

132 Language Acquisition [OELA], 2019). Outcome studies that examined which type of

133 educational programs for ELs is more effective have yielded mixed findings (Calderón et al.,

134 2011; May, 2008; Slavin \& Cheung, 2005). However, as Barrow and Markman-Pithers (2016)

135 pointed out, the inconsistency can be attributed to the lack of consensus on the goal of

136 educational programs for ELs amongst researchers (i.e., improving English proficiency vs.

137 becoming proficient bilingual speakers). 
We argue that regardless of the goal of a specific educational program, a program can

only be effective when there is congruence among the specified goals of a program, teachers' use of instructional language, and the linguistic needs of the children in the program. This congruence and the fundamental question of whether a particular educational program is

142 appropriate for certain ELs cannot be achieved or answered without assessing both languages to

143 understand the dual language profiles and corresponding linguistic needs of ELs. Currently,

144 Spanish proficiency is not routinely assessed in the EL identification process. Federal policies do 145 not specify particular procedures for identifying students as ELs but only mandate that states or 146 districts have procedures in place for accurately identifying students as ELs "in a timely, valid, 147 and reliable manner so that they can be provided the opportunity to participate meaningfully and 148 equally in the district's educational program" (U.S. Department of Education, 2015). All districts 149 require a home language survey to determine the language parents and students use at home 150 followed by an English language proficiency assessment. Of the 46 states with publicly available 151 information about EL identification procedures, only four states recommend or encourage 152 districts to assess students' home language proficiency as part of the EL identification and 153 program placement process (Boyle et al., 2015). Regarding English proficiency, states or even 154 districts within the same state vary in the proficiency tests administered and the cutoff points or 155 criteria used to determine EL status (Boyle et al., 2015; Tanenbaum et al., 2012), which could 156 potentially result in a student identified as an EL in one district to be considered as a proficient 157 English user in another. Additionally, state policies on the placement of EL students into a 158 particular type of educational program are more flexible: the majority of states do not have 159 formal policies on EL program placement but rather allow local discretion in determining 160 students' placement into the educational programs each district offers (Tanenbaum et al., 2012). 
161 To summarize, under current policies, in any given educational program for ELs, teachers may

162 encounter a mixed group of children with varying levels of English and the home language

163 because of (a) the lack of emphasis on testing students' home language, (b) the inconsistency in

164 criteria used to determine EL status at the state level, and (c) the flexibility in student placement

165 in EL programs at the local level.

166 Understanding whether linguistic variations in Spanish-speaking ELs are due to random

167 individual variability or due to systematic differences across distinct dual language profiles is

168 key to improving the congruence among EL students' linguistic needs, teachers' use of

169 instructional language, and educational programs for student placement. Educationally, if

170 Spanish-speaking ELs exhibit distinct language profiles, identifying these profiles would

171 facilitate the placement of EL students into the most appropriate educational programs so that the

172 instructional language aligns with specific types of students' linguistic strengths and needs.

173 Clinically, understanding language profiles may help identify Spanish-speaking ELs who may be 174 struggling in English and Spanish early on so that their progress in both can be monitored and

175 intervention can be initiated if needed.

\section{Language Profiles using Latent Profile Analysis}

177 In recent years, some studies have started to use "person-centered" statistical methods,

178 such as latent profile analysis (LPA), to identify language profiles in Spanish-English bilingual

179 children. Latent profile analysis is a type of finite mixture model used to express the overall

180 distribution of one or more variables as a mixture of a finite number of component distributions

181 (Masyn, 2013; B. O. Muthén, 2004). One feature for all mixture models is that the components

182 or component memberships are not directly observed but are latent. In other words, mixture

183 models are used to identify some number of unknown subgroups or profiles of persons using 
184 individual-level characteristics to express the overall population distribution (Masyn, 2013).

185 Compared to traditional clustering analytic approaches, model-based approaches like LPA offer

186 greater flexibility in several ways: (a) LPA allows users to include covariates in the models; (b)

187 LPA models allow parameters such as means, variances, and covariances to vary across clusters;

188 (c) statistical tests of model fit are conducted to aid the process of finding the optimal model

189 solution (Pastor et al., 2007; Woo et al., 2018). We summarized the number of participants

190 excluded in each step of the exclusion criteria and the distribution of excluded participants from

191 each school district in Supplemental Material S1. Thus, LPA is suitable for testing the presence

192 of latent subgroups or profiles in a population and is a preferred method in psychological and

193 organizational research due to its model-based approach and the flexibility in its model

194 specification procedure (Kapantzoglou et al., 2015; Lubke \& Muthén, 2005; Pastor et al., 2007;

195 Woo et al., 2018).

196 We identified five studies that investigated language-related profiles in Spanish-English 197 bilingual children in the literature (Gonzalez et al., 2016; Halpin et al., 2021; Kapantzoglou et 198 al., 2015; Lonigan et al., 2018; López \& Foster, 2021). These studies vary regarding the age of 199 the participants, the domains included in the profiles (e.g., language, literacy, cognitive, 200 academic achievements), and whether skills in one or both languages are considered in the 201 analyses (see Table 1 for a summary). Halpin et al. (2021) was the only study that used both 202 Spanish and English oral language skills to identify distinct language profiles based on a sample 203 of 161 bilingual preschoolers (Halpin et al., 2021). This study used scores from six subtests from 204 the Bilingual English Spanish Assessment (BESA; Peña et al., 2014), including phonology, 205 semantics, and morphosyntax in Spanish and in English. The authors identified a four-profile 206 solution as the optimal solution, including: (a) a low balanced bilingual group with a relative 
207 weakness in morphosyntax in both languages, (b) a high balanced bilingual group, (c) an uneven 208 profile with high Spanish skills and low English skills, and (d) an uneven profile with low

209 Spanish skills and high English skills. Notably, no study has examined the oral language profiles

210 in a school-aged sample based on both English and Spanish language abilities.

\section{The Current Study}

212 The objective of this study was to identify and describe potential dual oral language

213 profiles in a large-scale sample of school-aged Spanish-speaking children designated as ELs by

214 their school district. This study extends existing work on language profiles in Spanish-English

215 bilingual children in three unique aspects. First, this study focuses on a subset of bilingual

216 children, school-aged ELs, a population that has not been examined in previous work using LPA.

217 Identifying distinct dual language profiles in this specific population will provide helpful insights

218 to improve the congruence between EL students' linguistic needs and available educational

219 programs.

220 Second, this study includes English and Spanish oral language measures derived from

221 narrative language samples. Narrative sample analysis is a recommended approach when

222 assessing children from culturally and linguistically diverse backgrounds (Bedore et al., 2010;

223 Ebert, 2020; Gutiérrez-Clellen, 2002; Rojas \& Iglesias, 2006). Narrative sample analysis has

224 high ecological and content validity as it involves eliciting connected language production in 225 functional communication and academic contexts (Castilla-Earls et al., 2020; Gutiérrez-Clellen

226 et al., 2000; Peña et al., 2006). Oral narrative skills are strongly associated with literacy skills in

227 bilingual children (Miller et al., 2006; Rojas et al., 2019). Narrative sample analysis is versatile

228 because it can be used with children from preschoolers to school-aged children and can be

229 analyzed in different ways to derive quantitative and qualitative measures to index multiple 
230 language domains, providing rich information about a child's expressive language ability

231 (Castilla-Earls et al., 2019; Heilmann et al., 2016). It is also considered as a least-biased

232 assessment approach in comparison to traditional standardized tests as storytelling is common in

233 many cultures (Bitetti et al., 2020; Fiestas \& Peña, 2004).

234 Lastly, when selecting indicator variables for the LPA, we intentionally selected two

235 microstructure measures that index specific language domains and two measures that represent

236 language proficiency and productivity at the global level for each language. At the

237 microstructure level, we focused on syntax as measured by the subordination index (SI) and

238 lexical diversity as measured by moving average type-token ratio (MATTR). These two

239 constructs are commonly examined in previous work that used LPA with Spanish-English

240 bilingual children (Gonzalez et al., 2016; Halpin et al., 2021; Kapantzoglou et al., 2015). At the

241 global level, we included a measure of narrative proficiency using Narrative Structure Scheme

242 (NSS) and a measure of verbal productivity using words per minute (WPM). Both NSS and

243 WPM are developmentally sensitive measures for the targeted age group for both Spanish and

244 English (Heilmann et al., 2010) and have been used as global measures that represent overall

245 integration of the multiple demands of narrative formulation and verbal production (see Bitetti \&

246 Hammer, 2021; Lucero, 2015; Méndez et al., 2018 for studies on NSS and see Heilmann et al.,

247 2008; Miller et al., 2006; Rojas \& Iglesias, 2013 for studies on WPM). These four selected

248 measures each taps a different aspect of language performance and can be compared across

249 languages (Miller et al., 2006). Combined, these measures provide a broad index of oral

250 language ability in each language and were collectively used as indicator variables in the latent

251 profile analysis. 
We hypothesize that at least three types of dual language profiles may emerge, including

253 a group of children with high proficiency in Spanish and low proficiency in English (Spanish-

254 dominant), a group of children with high proficiency in English and low proficiency in Spanish

255 (English-dominant), and a group of children with relatively similar English and Spanish

256 proficiency (balanced - proficiency level not specified). Despite the number of profiles identified

257 in previous studies, these three types of profiles have been consistently revealed (Gonzalez et al., 258 2016; Halpin et al., 2021; Lonigan et al., 2018; López \& Foster, 2021).

\section{Method}

260 Participants

261 This study involved secondary analysis of archival and deidentified data drawn from a

262 large-scale cross-sectional study designed to examine factors that influence language and literacy

263 development of Spanish-English bilingual children during the initial years of schooling (Francis

264 et al., 2005). Secondary analyses were approved by the institutional review board at the

265 University of Delaware and the University of Texas at Dallas. Participants of the large-scale

266 study were children in grades kindergarten through third $(\mathrm{N}=1,532)$ enrolled in 13 different

267 schools in two geographic regions of Texas: a large urban area in southeastern Texas $(\mathrm{N}=532$

268 participants in 6 schools in the Houston Independent School District) and a smaller urban area

269 near the border between Texas and Mexico known as the Rio Grande Valley $(\mathrm{N}=1,012$

270 participants in 7 schools in the Brownsville Independent School District). All students were

271 designated as English learners whose English skills were deemed to be insufficient to perform

272 adequately in all-English classrooms. All children were enrolled in similar transitional bilingual

273 programs in which they were academically instructed primarily in Spanish at the beginning and

274 then gradually transitioned to English, with the expectation that they would be English proficient 
275 by third grade. At the time of recruitment, these children had not been identified as having a 276 present or past disability by their school districts.

277 A subset of participants from the original study was included for this present study based 278 on the following inclusion criteria: (a) contributed narrative samples in English and Spanish, and 279 (b) each narrative sample contained at least five complete and intelligible utterances with $75 \%$ or 280 more of the number of total words (NTW) produced in the target language. Of the 1,532

281 children, 595 (235 children from Houston and 359 from Rio Grande Valley) did not contribute a

282 language sample in both languages due to various reasons (e.g., absent during test date, poor

283 audio quality), 5 had fewer than five complete and intelligible utterances in at least one language

284 sample, and 30 had less than 75\% NTW in the target language. Additionally, 37 participants

285 were excluded due to a suspicion of data collection procedure error. The testing procedure in

286 English and Spanish should have been within two months apart, yet we found 37 participants

287 who were tested in English more than three months later than the Spanish testing procedure. We

288 excluded these participants conservatively to avoid possible confound of maturation effect in one

289 language over the other. An additional 18 participants were excluded as their observations were

290 detected as multivariate outliers (see Results section). Thus, the final analysis dataset included

291847 Spanish-speaking ELs (451 girls, 396 boys) from 173 classrooms from 13 schools, including

292125 kindergarteners, 197 first graders, 249 second graders, and 276 third graders.

\section{Procedures}

294 As part of the large-scale study, narrative retell language samples in Spanish and English 295 were elicited from the participants using a wordless picture book Frog, Where Are You? (Mayer, 296 1969). For all participants, testing sessions were first administered in Spanish and were

297 replicated in English approximately 1 week later. The examiners were proficient Spanish-English 
298 bilingual speakers. Different examiners elicited the narrative samples in each language. During

299 the narrative elicitation task, the examiner sat across from the child and read a scripted version of

300 the story in the target language. Then the examiner gave the child the book and requested that the

301 child retell the story using the following cue: "Now, tell me what happened in the story" /

302 “Ahora, cuéntame lo que pasó en este cuento.” Examiners were only permitted to provide

303 backchannel responses (e.g., "aha," "sí', “yes”) or repeat the child's last utterance to encourage

304 continued narration. Examiners were explicitly instructed not to provide additional information

305 or answer questions from the participants.

306 All narratives were digitally recorded and transcribed using Systematic Analysis of

307 Language Transcripts (SALT; Miller \& Iglesias, 2019) transcription format following

308 conventions for bilingual language samples (cf. Rojas \& Iglesias, 2013, p. 635). Complete and

309 intelligible utterances were defined based on SALT conventions and excluded utterances with

310 unintelligible segments, abandoned utterances, interrupted utterances, and non-verbal utterances.

311 Code-switching was coded at the word level, and sentences where code-switching occurred were

312 included in the analysis set. The mean number of complete and intelligible utterances was 37.33

$313(S D=11.25)$ in English and $38.78(S D=11.25)$ in Spanish. Each transcriber completed an

314 extensive training process requiring approximately 10 hours of working with a lab manager. For

315 all English and Spanish transcripts, an initial transcription was completed by a transcriber, which

316 was reviewed by a second transcriber to correct any transcription errors. The final transcript was

317 then coded for narrative structure using the Narrative Structure Scheme (NSS) (Heilmann et al.,

318 2010). Twenty transcripts in English and 20 transcripts in Spanish were randomly selected to

319 determine reliability of the language samples at three levels: protocol accuracy (i.e., adherence to

320 SALT transcription conventions), transcription accuracy (i.e., segmentation of words and 
321 utterances), and NSS coding agreement. Protocol accuracy ranged from 98\% to 100\% in English

322 and $94 \%$ to $99 \%$ in Spanish. Transcription accuracy ranged from $90 \%$ to $98 \%$ in English and

$32391 \%$ to $99 \%$ in Spanish. For NSS coding agreement, Krippendorff's alpha, a measure of inter-

324 rater reliability that supports interval data, was calculated (Krippendorff, 2011). Alphas for the

325 NSS were .74 in English and .60 in Spanish.

\section{Measures}

327 Spanish and English oral language measures were calculated from the narrative

328 transcripts using SALT. Four measures were calculated in Spanish and English, including the

329 subordination index (SI), moving average type-token ratio (MATTR), Narrative Structure

330 Scheme (NSS) total score, and words per minute (WPM). As described in detail in the

331 introduction, each measure taps a different aspect of language performance, including syntax,

332 vocabulary diversity, narrative proficiency, and verbal productivity and is comparable across

333 languages (Miller et al., 2006). Combined, these measures provide a broad index of oral

334 language ability in each language and were collectively used in the latent profile analysis.

335 The SI (Scott \& Stokes, 1995) is a measure of syntactic complexity that produces a ratio

336 of the total number of clauses (including both main and subordinate clauses) to the total number

337 of C-units. SI is a well-suited and sensitive measure of syntactic complexity that captures

338 complex sentence development in monolingual and bilingual young school-aged children (Alt et

339 al., 2016; Gutiérrez-Clellen, 1998; Gutiérrez-Clellen \& Hofstetter, 1994; Heilmann et al., 2010).

340 Previous work has also shown that SI continues to develop through the school years for English-

341 speaking and Spanish-speaking children (Castilla-Earls \& Eriks-Brophy, 2012; Gutiérrez-Clellen

$342 \&$ Hofstetter, 1994). 
The MATTR (Covington \& McFall, 2010) is a measure of lexical diversity and is derived

344 by using a moving window of fixed length (e.g., 10 words, 20 words) to calculate the ratio of

345 unique words to the number of total words for each successive window and averaging the

346 estimated ratios for each window. MATTR was selected as a measure of lexical diversity over

347 number of different words (NDW), type-token ratio (TTR), and lexical $D$ because MATTR is

348 particularly robust to variations in language sample length for English and Spanish language

349 samples and was endorsed as a stronger indicator of lexical diversity compared to TTR and

350 lexical $D$ (Fergadiotis et al., 2013, 2015; Kapantzoglou et al., 2019). In our analyses, we used a

351 15-word moving window based on the lowest number of total words (NTW) in the entire sample.

352 The NSS is a measure of children's ability to produce a coherent narrative (Miller et al.,

353 2006). This measure consists of seven categories including four story grammar categories

354 (introduction, character development, conflict/resolution and event/reaction, and conclusion),

355 and three additional elements (use of mental and emotional states, referencing/listener

356 awareness, and cohesion). Each category was scored on a six-point scale from 0 to 5 . SALT uses

357 scores from the seven categories to calculate a total score (maximum score $=35$ ).

The WPM is a measure of verbal productivity calculated by dividing NTW by the

359 duration of the transcript in minutes. This measure has been proposed as an index of language

360 proficiency for second language learners (Riggenrach, 1991) and was found to be strongly

361 correlated with age and second language proficiency in EL students (Miller et al., 2006).

362 We included code-switched words when deriving SI, WPM, and NSS but excluded code-

363 switched words when calculating MATTR. Considering that SI, WPM, and NSS measure gross

364 language constructs beyond vocabulary, removing code-switched words out of their productive

365 context results in measures not representative of the constructs they intend to measure. A 
366 previous study found that including or excluding code-switching when calculating MATTR

367 produced different values within the same group of samples (Hiebert \& Rojas, 2021). In order to

368 avoid inflating MATTR, we excluded code-switched words when calculating MATTR.

\section{Model Enumeration}

We used Mplus (version 8.5) to run all LPA analyses. All LPA models were estimated

371 using maximum likelihood estimation with robust standard errors ("Estimator = MLR"), which is

372 the default and recommended estimator for LPA (Muthén \& Muthén, 2017). To avoid invalid

373 parameter estimates resulting from a local solution, which is a common issue in LPA analyses,

374 previous studies recommend using multiple random sets of starting values (Berlin, Williams, \&

375 Parra, 2014; Hipp \& Bauer, 2006). Thus, all models were estimated with 500 random starts and

37620 iterations at the final optimization stage by using the "Starts $=500,20$ " command. We

377 followed recommendations from Masyn (2013) and Nylund-Gibson and Choi (2018) for the

378 model enumeration process. We started with a one-profile model and gradually increased the

379 number of profiles estimated, one profile at a time, until the estimated model ceased to be well-

380 defined (e.g., models fail to converge, small condition number, small size of the minimal

381 profile).

Additionally, LPA allows flexible specifications of the within-class variance-covariance

383 structure (i.e., mean/variance/covariance could be set to vary across profiles or constrained to be

384 equal across profiles) (Masyn, 2013; Vermunt \& Magidson, 2002). Four types of within-class

385 variance-covariance structures $\left(\Sigma_{\mathrm{k}}\right)$ are commonly specified from the most to the least restrictive:

386 (a) Class-invariant, diagonal (i.e., means allowed to vary across profiles, variance constrained to

387 be equal, and covariance constrained to be zero; referred to as Model A hereafter); (b) Class-

388 varying, diagonal (i.e., means allowed to vary, variance allowed to vary, covariance constrained 
389

390

391

392

393

394

395

396

397

398

399

400

401

402

403

404

405

406

407

408

409

410

411

to zero; referred to as Model B); (c) Class-invariant, unrestricted (i.e., means allowed to vary, variance and covariance constrained to be equal; referred to as Model C); and (d) Class-varying, unrestricted (i.e., means, variance, and covariance all allowed to vary; referred to as Model D).

Masyn recommended that one consider all four within-class variance-covariance structures given that the specification of these parameters can influence the formation of the latent profiles. Thus, we conducted four sets of model enumeration sequences (from one-profile until K-profile where the model stopped to be well-defined), one set for each of the four types of $\Sigma_{\mathrm{k}}$. From here on, we will refer to each estimated model by using the letter that indicates a particular $\Sigma_{\mathrm{k}}$ specifications followed by the number of profiles specified (e.g., Model A3 = a 3-profile model with classinvariant, unrestricted $\Sigma_{\mathrm{k}}$ ).

\section{Model Interpretation and Selection}

All models estimated were first compared within each $\Sigma_{\mathrm{k}}$ and the four candidate models were then compared to yield the optimal profile solution (Masyn, 2013). Even though LPA provides a variety of model fit statistics, the selection of the optimal solution is less straightforward than one would expect because the combination of all fit statistics rarely converges on one single model (Nylund-Gibson \& Choi, 2018; Nylund et al., 2007). Previous work has recommended that one consider a combination of model fit statistics, classification diagnostics, theoretical justification, and model interpretability when selecting the optimal profile solution (Masyn, 2013; B. O. Muthén, 2003; Nylund-Gibson \& Choi, 2018).

We examined all estimated models in four steps to select the optimal solution. First, we excluded models that are not well-defined. Indicators of a weakly defined model include failure to converge, lack of replication across a set of number of random starts, and small condition number $\left(<10^{-6}\right)$. Second, we examined a variety of model relative fit indices and model 
412 classification diagnostic indices. For relative fit indices, we considered the sample-size adjusted

413 Bayesian Information Criterion (SABIC), Consistent Akaike's Information Criterion (CAIC),

414 Approximate Weight of Evidence Criterion (AWE), Vuong-Lo-Mendell-Rubin Likelihood Ratio

415 Test (VLMR-LRT; Lo, Mendell, \& Rubin, 2001), Bootstrap Likelihood Ratio Test, and Bayes

416 Factor (BF). SABIC, CAIC, and AWE are the three most common information criteria fit indices

417 used in LPA; lower values of SABIC, CAIC, and AWE indicate better fit than higher values

418 (Masyn, 2013). VLMR-LRT and BLRT are relative fit indices that test two nested models (e.g.,

419 K profile model compared to K-1 profile model). A significant $p$-value indicates that the model

420 with the additional profile significantly improves upon the previous model. Bayes Factor is

421 another relative fit index the compares fit between two nested models (e.g., $\mathrm{K}$ vs $\mathrm{K}+1$ ). A BF

422 value above 10 is considered strong evidence for model $\mathrm{K}$ over model $\mathrm{K}+1$. Regarding model

423 classification diagnostic indices, we examined entropy, average posterior probabilities (AvePP),

424 and the minimum estimated profile size in each solution. These three indices provide model

425 classification diagnostic information by evaluating the precision of the latent profile assignment

426 for individual by a specified model (Masyn, 2013). Entropy indicates the overall precision of

427 model classification for the whole sample (Ramasway, DeSarbo, Reibstein, \& Robinson, 1993).

428 Entropy is a value between 0 and 1: an entropy value near 1 indicates good posterior

429 classification. AvePP is calculated by averaging the posterior probability for every participant

430 assigned. AvePP values above .70 indicates well-separated profiles and adequate latent profile

431 assignment (Nagin, 2005). The minimum profile size is the smallest estimated profile size among

432 all the latent profiles estimated in each model. A small minimum profile size (e.g., $<3 \%$ of the

433 whole sample) can be an indicator of data overextraction (Masyn, 2013; Nylund-Gibson \& Choi, 434 2018). 
In addition to the relative fit and model classification indices described above, Masyn

436

437

438

439

440

441

442

443

444 (2013) recommends using a one-profile LPA model for class-invariant, unrestricted $\Sigma_{\mathrm{k}}$ specification (i.e., Model C1) as an absolute fit benchmark. This model specification is considered as a "minimum-goodness-of-fit" (Masyn, 2013, p.593) because it was only informed by the sample means and covariance. In the third step of the model selection process, we prioritized models with a better (larger) log likelihood (LL) value and better (smaller) relative fit indices compared to the benchmark model. Lastly, once the optimal solution was selected based on model fit indices considered in the first three steps, we examined students' performance on all measures in each profile identified by the optimal solution to confirm that the selected model was theoretically and conceptually meaningful (Grimm et al., 2019; B. O. Muthén, 2003).

\section{Results}

\section{Preliminary Data Analysis}

Prior to LPA, a series of preliminary analysis of raw data was conducted to check for possible multivariate outliers, skewness, kurtosis, and multicollinearity. Mahalanobis distance was calculated for each observation to detect multivariate outliers: data from 18 participants had a $p$ value of less than .001 and were thus excluded from analysis $(\mathrm{N}$ included sample $=865, \mathrm{~N}$ analysis sample $=847)$. Next, skewness and kurtosis were examined for each of the eight variables: all values were within acceptable levels (all skewness values $<.8$ and all kurtosis values $<3$ )(Cain et al., 2017; Tabachnick \& Fidell, 2012). Intercorrelations among measures were not sufficiently high to warrant concerns regarding multicollinearity (i.e., $\leqslant 0.8)$. The highest significant correlation was between English WPM and English NSS score $(r=0.56, p$ $<.001)$. After these steps, all variables were standardized into Z-scores to facilitate model convergence. Descriptive statistics of all variables used in the LPA are reported in Table 2. 
Additionally, we examined multi-level dependencies within the dataset because

participants were nested within classrooms and schools. We used Intraclass correlation coefficients (ICCs) which calculate the proportion of overall variance explained in one variable explained by a macro unit (level 2) and indicate the degree to which data from participants within a classroom and a school are non-independent (Pornprasertmanit et al., 2014). The ICC values for level 2 (classroom) and level 3 (school) are respectively .33 and .05, which indicates non-independence of participants at the classroom level. Thus, in all LPA analyses, we added two commands "Type $=$ Complex Mixture" and "Cluster $=$ Class" to adjust standard errors of all parameter estimates and fit statistics to account for the nesting structure of participants within classrooms (López \& Foster, 2021; Muthén \& Muthén, 2017).

\section{LPA Results}

We started the model enumeration procedure by fitting a one-profile model for each of four within-class variance-covariance specifications. We stopped the model enumeration process at $K=6$ profiles for each of four $\Sigma_{\mathrm{k}}$ specifications because after $K=6$, the model for the most restrictive $\Sigma_{\mathrm{k}}$ with the least number of parameters estimated (i.e., Model A7) ceased to be wellidentified indicated by a lack of replication across the set number of random starts. Fit statistics for all models estimated are displayed in Table 3.

In the first step of the model selection and interpretation process, we excluded models that were not well-defined. Among the 24 models estimated (Models A1 - D6), 20 models were well-defined and were further examined (Models A1-A6, B1-B6, C1-C6, D1-D2; see Table 3). In the second step, we examined model fit indices and classification diagnostic indices within each set of $\Sigma_{\mathrm{k}}$ specifications to select a preferred model for each set. Regarding information criteria indices, we prioritized models where multiple indices converge (e.g., model A6, B5, C4). 
481 Bolded values in Table 3 indicate the value that correspond to the "best" fit index within each

482 set. Regarding relative fit indices, BLRT was not considered because BLRT values for all

483 models preferred the model with more profiles estimated and accordingly did not provide helpful

484 information. We determined that a preferred model needs to significantly improve upon a

485 previous model based on either VLMR-LRT or BF. Entropy was examined but not used for

486 model selection because it is not a sensitive nor specific index for the goodness of fit: latent

487 profile assignment error can happen in models with entropy values close to 1 and entropy values

488 can also be low in models with good fit (Masyn, 2013; Nylund-Gibson \& Choi, 2018). AvePP

489 values for all models estimated were above .70 (Nagin, 2005; Nylund-Gibson \& Choi, 2018).

490 Lastly, we determined that a preferred model required a minimum profile size of $3 \%$ of the total

491 sample. Based on all available model fit indices, a preferred model was selected for each set,

492 yielding four candidate models: Models A6, B5, C4, and D2. In the third step, these four models

493 were compared against each other and against the benchmark model, Model C1, which is the

494 one-profile model for the class-invariant, unrestricted $\Sigma_{\mathrm{k}}$ specification. Figure 1 displays four

495 panels displaying LL, SABIC, CAIC, and AWE values for all estimated models. The dashed

496 lines correspond to the index value of the benchmark model. In terms of log likelihood value,

497 Models B5, C4, and D2 have a better log likelihood value than the benchmark model. All

498 information criteria indices favored Model C4, with the lowest SABIC and CAIC values among

499 all estimated models. Though the AWE value for the Model C5 was not the lowest among all

500 estimated models, it was the lowest among the four candidate models. Thus, we selected Model

$501 \quad$ C4 as the final optimal solution.

502 Profile Characteristics 
The optimal solution, Model C4, represents a four-profile solution. Means and standard

504 deviations of the English and Spanish oral language measures for each identified latent profile

505 are displayed in Table 4 (raw values are reported to facilitate interpretation). Figure 2 displays

506 students' performance on all measures in English and Spanish for each profile using Z-scores for

507 comparability. Figure 3 represents an alternative view of students' performance, allowing a

508 comparison of dual language proficiency within and across each of the four profiles. It is

509 important to note that students' performance on each measure are relative to the sample

510 (Spanish-speaking ELs). Figure 4 displays grade distribution in each of the four latent profiles

511 identified. Each profile was termed based on the relative proficiency across English and Spanish,

512 English level, and Spanish level.

$513 \quad$ Profile 1: Balanced-average (average Spanish and English). Profile 1 was the largest

514 profile in size and included 655 children ( $77.33 \%$ of the sample). There were 83 children in

515 Grade K, 146 in Grade 1, 196 in Grade 1, and 230 in Grade 3. Children with this profile showed

516 similar average levels of English and Spanish performance. Z-scores for Spanish measures

517 ranged from -.15 to .12 and for English measures ranged from -.01 to .16.

$518 \quad$ Profile 2: Spanish-dominant (average Spanish, low English). Profile 2 includes 58

519 children (6.85\%). This group consists of 17 children from Grade K, 22 from Grade 1, 17 from

520 Grade 2, and 2 from Grade 3. Children with this language profile displayed average Spanish

521 performance and low English performance. Z-scores for Spanish language measures ranged from

$522-.34$ to -.22 . Z-scores for three English measures were more than $1 S D$ below the sample mean: -

5231.23 for SI, -1.29 for NSS, -1.28 for WPM. This group of children also demonstrated a particular

524 relative weakness in English vocabulary: the Z-score for English MATTR was -2.55. 
Profile 3: English-dominant (low Spanish, average English). Profile 3 includes 46

526

527

528

529

530

531

532

533

534

535

536

537

538

539

540

541

542

543

544

545

546

547

children (5.43\%) with 16 from Grade K, 17 from Grade 1, 7 from Grade 2, and 6 from Grade 3.

Children in this profile demonstrated the opposite pattern from children in Profile 2. They

performed at average levels for English (Z-scores ranged from -.06 to .12) but at low levels for

Spanish, showing an English-dominant profile. The relative vocabulary weakness of the weaker

language evidenced in Profile 2 was also observed in this profile: though Z-scores for Spanish

SI, NSS, and WPM were respectively $-0.86,-1.16$, and -1.16 , the Z-score for Spanish MATTR was -2.43 .

Profile 4: Balanced-high (high Spanish, high English). The last profile includes 88 children (10.39\%) and includes 9 children from Grade K, 12 from Grade 1, 29 from Grade 2, and

38 from Grade 3. Children in this profile showed high levels of performance in both Spanish and English. Relative to other children in this sample, children in this profile demonstrated the highest scores in all eight measures. Z-scores for English measures ranged from .35 to .87. Zscores for Spanish measures ranged from .17 to 1.78, with a particular strength in Spanish syntax.

\section{Post-hoc Exploratory Analysis Comparing Profile 4 (Balanced-high) with Monolingual}

\section{Samples}

Children in Profile 4 evidenced the highest levels of both English and Spanish language ability in general relative to other ELs in the whole sample. By current federal definition, an EL is a student with "limited English proficiency", which is further defined as a student whose difficulty in using English "may be sufficient to deny the individual the ability to successfully achieve in classrooms where the language of instruction is English" (Linquanti et al., 2016, p.10). To gain insights into the English and Spanish proficiency of ELs in Profile 4 in 
548 comparison to a broader population than the current sample, we conducted post-hoc exploratory

549 analyses to respectively compare their language ability with monolingual English-speaking peers

550 and monolingual Spanish-speaking peers. SALT Research Version 2020 features several large

551 normative reference databases and allows users to build a specific comparison database based on

552 language sample context (e.g., play, story retell, expository, persuasion, etc.), age, and/or grade

553 criteria (Miller \& Iglesias, 2019, see https://www.saltsoftware.com/resources/databases for

554 detailed information of the normative databases available). Samples in the user-built comparison

555 database can also be matched to a given set of language samples on length measured by NTW,

556 the number of utterances, or the amount of elapsed time.

557 For our purposes, we selected language samples from the monolingual English Narrative

558 Story Retell database and the Monolingual Spanish Story Retell database to build two matched

559 reference datasets, a monolingual English and a monolingual Spanish dataset. The Narrative

560 Story Retell database contains transcripts of elicited story retells from 529 typically developing

561 monolingual English-speaking children from preschool to $6^{\text {th }}$ grade located in Wisconsin and

562 California (Miller et al., 2015b). The Monolingual Spanish Story Retell contains elicited story

563 retell narratives from 1,068 monolingual Spanish-speaking children from $1^{\text {st }}$ to $3^{\text {rd }}$ grade residing

564 in Guadalajara, Mexico (Miller, Andriacchi, \& Nockerts, 2015a; Goldenberg, NIH NICHD

565 R01HD44923). Each student in Profile 4 (Balanced-high) was individually matched to a sample

566 from the monolingual English reference dataset and a sample from the monolingual Spanish

567 reference dataset by sex, grade, and language sample length based on the number of complete

568 and intelligible utterances.

569 Means and standard deviations of Spanish and English oral language measures for Profile

5704 (Balanced-high), matched monolingual English samples, and matched monolingual Spanish 
571 samples are depicted in Figure 5. Compared to the monolingual English sample, children in

572 Profile 4 achieved comparable levels of English syntax $\left(\mathrm{M}_{\text {Profile4 }}=1.2, \mathrm{M}_{\text {Norm }}=1.22, p=.11\right)$

573 and English verbal productivity $\left(\mathrm{M}_{\text {Profile4 }}=98.4, \mathrm{M}_{\mathrm{Norm}}=93, p=.19\right)$ but scored significantly

574 lower on English MATTR $\left(\mathrm{M}_{\text {Profile4 }}=0.82, \mathrm{M}_{\text {Norm }}=0.86, p<.001\right)$ and English NSS $\left(\mathrm{M}_{\text {Profile4 }}=\right.$

$\left.57520.84, \mathrm{M}_{\mathrm{Norm}}=22.74, p=.006\right)$. In terms of Spanish measures, children in Profile 4 performed

576 similarly or better on all Spanish measures compared to the monolingual Spanish normative 577 sample: $\operatorname{MATTR}\left(\mathrm{M}_{\text {Profile4 }}=0.86, \mathrm{M}_{\text {Norm }}=0.86, p=.47\right), \mathrm{WPM}\left(\mathrm{M}_{\text {Profile4 }}=82.82, \mathrm{M}_{\text {Norm }}=\right.$ $57883.11 p=.93)$, with significant differences observed in $\mathrm{SI}\left(\mathrm{M}_{\text {Profile4 }}=1.38, \mathrm{M}_{\text {Norm }}=1.25, p<\right.$.

$579001)$ and NSS $\left(M_{\text {Profile4 }}=23.15, \mathrm{M}_{\text {Norm }}=20.95 p=.004\right)$, both favoring children in Profile 4.

\section{Discussion}

581 Summary of Latent Dual Language Profiles

The goal of this study was to identify and describe dual language profiles in English and

583 Spanish oral language skills in a large-scale sample of Spanish-speaking children designated as

584 ELs by their school district. Findings from this study revealed four dual language profiles,

585 including one Spanish-dominant profile (Profile 2 average Spanish, low English), one English-

586 dominant profile (Profile 3 low Spanish, average English), and two balanced profiles (Profile 1

587 Balanced-average; Profile 4 Balanced-high). These four dual language profiles confirmed our

588 hypothesis on the types of language profiles that would emerge and are largely consistent with 589 prior studies that examined language-related profiles in Spanish-English bilingual children. In

590 the past five years, a small body of literature has emerged to understand the linguistic diversity in 591 Spanish-English bilingual children (Gonzalez et al., 2016; Grimm et al., 2019; Halpin et al., 592 2021; Kapantzoglou et al., 2015; Lonigan et al., 2018; López \& Foster, 2021). These studies 593 have shown that Spanish-English bilingual children display distinct profiles in Spanish oral 
594 language and nonverbal cognitive abilities (Kapantzoglou et al., 2015), emergent literacy skills

595 (Gonzalez et al., 2016; Lonigan et al., 2018), Spanish and English reading skills (Grimm et al.,

596 2019), phonology and morphosyntactic skills (Halpin et al., 2021), and academic achievement

597 skills (López \& Foster, 2021). The types of dual language profile patterns that this study

598 identified converged with previous studies. López and Foster (2021) found one English-

599 dominant, one Spanish-dominant, and two balanced profiles in the academic achievement of

600 Spanish-English bilingual children enrolled in Head Start programs. In a younger sample of

601 Spanish-English bilingual preschoolers from Head Start programs, Lonigan and colleagues

602 (2018) identified two English-dominant profiles, three balanced bilingual profiles, and four

603 Spanish-dominant profiles.

604 Given that most of the previous studies used different indicator measures across domains,

605 we specifically compared our findings with two previous studies that focused exclusively on oral

606 language measures (Halpin et al., 2021 and Kapantzoglou et al., 2015). Of the two studies,

607 Halpin et al. (2021) was the only study that examined oral language measures in both English

608 and Spanish. Despite methodological differences - Halpin et al. (2021) used measures from a

609 standardized norm-referenced test (BESA; Peña et al., 2014) and this current study used

610 narrative language sample analyses - both studies revealed two balanced profiles and two

611 uneven profiles with an English-dominant profile and a Spanish-dominant profile, providing

612 convergent evidence supporting the dual language profiles emerged from this study. However,

613 we noted one difference in results between this current study and both Halpin et al. (2021) and

614 Kapantzoglou et al. (2015). Participants in Halpin et al. (2021) displayed the weakest scores in

615 the morphosyntax domain across profiles, yet a similar pattern of a uniform low performance in

616 syntax across profiles was not observed in this study. On the other hand, Kapantzoglou et al. 
617 (2015) discovered one small low Spanish grammaticality group with particularly low

618 grammaticality ability and average performance in other measures such as lexical diversity,

619 utterance length, and nonword repetition. These discrepancies across studies in participants'

620 syntax performance may be attributed to the differences in aspects of syntax measured (i.e.,

621 morphosyntax in Halpin et al., 2021, grammaticality in Kapantzoglou et al., 2015, and syntactic

622 complexity in this study), tasks used to measure syntax (i.e., standardized assessment vs.

623 language sample analysis), and the chronological age of the sample (preschoolers vs. school-

624 aged children). Specifically, Halpin et al. (2021) focused on morphosyntax measured by the

625 morphosyntax subtests from BESA (Peña et al., 2014), which use cloze items as well as sentence

626 repetition to assess specific morphosyntactic structures in English (e.g., regular past tense,

627 negatives) and Spanish (e.g., articles, direct object clitics) selected to differentiate typical

628 language development and language impairment. Kapantzoglou et al. (2015) focused on

629 grammaticality as measured by the number of grammatical errors per terminal unit based on

630 narrative retell samples. This current study focused on syntactic complexity as measured by SI

631 based on narrative retell samples. Additionally, Halpin et al. (2021) involved participants

632 between 3 and 5 years while Kapantzoglou et al. (2015) and this study included young school-

633 aged participants. It is reasonable to expect developmental differences in bilingual children's

634 syntactic skills between preschool years and school years even using the same measurement tool,

635 and such differences may be magnified when different aspects of syntax are measured using

636 different measurement tools.

\section{A Unique Focus on ELs}

638 The sample in this study is particularly unique that they constitute a subset of Spanish-

639 English bilingual children that are designated as ELs by their school district. ELs are often 
640 considered and treated to be linguistically homogenous as ELs contrast with English proficient

641 students by definition (National Research Council, 2011). However, findings from this study

642 demonstrated substantial variations in English and Spanish abilities in the current sample of ELs.

643 Even though participants in this study are designated as students with limited English proficiency

644 by definition, participants in the overall best profile (i.e., Profile 4, Balanced-high) achieved

645 English performance on par with monolingual English-speaking peers in syntax measured by SI

646 and in verbal productivity measured by WPM. In stark contrast, children in the Spanish-

647 dominant profile (i.e., Profile 2) scored more than $1 S D$ lower than the sample average in English

648 across all measures. Similarly for Spanish, children in Profile 4 scored higher than monolingual

649 Spanish-speaking peers in three out of four measures (SI, MATTR, NSS), whereas children in

650 the English-dominant profile (i.e., Profile 3) scored more than $1 S D$ lower than the sample

651 average in three out of four measures (MATTR, NSS, WPM). The observed variability in both

652 languages is concerning because all children in this study were placed into similar transitional

653 bilingual educational programs. In these programs, children initially received academic

654 instruction in Spanish and were transitioned to all English instruction after third grade. Our

655 findings suggest that placing ELs with significantly different profiles into the same kind of

656 transitional program may not be appropriate given that the same model of instruction (i.e.,

657 Spanish first and English later) likely will not meet the specific needs of individual students with

658 drastically varied Spanish and English proficiency.

659 In addition, the presence of an English-dominant profile in our sample of ELs (i.e.,

660 Profile 3) cautions against making a priori assumptions regarding the home language proficiency

661 and language dominance pattern in ELs. In most states, the EL identification procedure involves

662 a home language survey that collects information on the language parents and the student use at 
663 home and an English language proficiency assessment if a student is considered a linguistic

664 minority based on the survey (Tanenbaum et al., 2012) without testing students' proficiency in

665 home language use. Three states (Connecticut, Rhode Island, and Texas) encourage school

666 districts to assess home language proficiency as part of their EL identification and program

667 placement procedure. Only one state (Nevada) requires districts to test the proficiency in home

668 language in ELs who are placed in dual language program within 60 days of student enrollment

669 (Boyle et al., 2015; Nevada Administrative Code $\S 388.630$, 2018). Despite a growing consensus

670 in the literature that bilingual children should be assessed in both of their languages (Hoff \&

671 Core, 2015), this recommendation is not yet reflected in state-level policies. Assessing the home

672 language as well as English before placing ELs in educational programs is crucial for two

673 reasons. First, a comprehensive understanding of language abilities ensures the congruence

674 between students' language knowledge and the use of instructional language. For example,

675 providing academic instruction in only Spanish for a student in Profile 3 who possesses average

676 English but low Spanish ability will not necessarily enhance their access to academic content.

677 Second, assessing both languages is the best way to accurately identity Spanish-English speaking

678 children who present with true language disorders. For instance, children in Profile 2 (Spanish-

679 dominant) who possess low English skills but adequate Spanish skills may be at risk of being

680 misidentified as having a language disorder if Spanish language skills are not considered during

681 assessment.

682 Uneven Performance across Languages and Domains

683 In addition to the large variability in both languages and distinct dual language profiles

684 identified, children in three profiles displayed uneven performance across language domains and

685 distinct patterns of unique strength or weakness in a specific domain in one of their two 
686 languages. Children in Profile 4 (Balanced-high) demonstrated a unique strength in Spanish 687 syntax compared to other measures in Spanish and English. Children in Profile 2 (Spanish688 dominant) and Profile 3 (English-dominant) demonstrated a mirrored pattern with a relative 689 weakness in vocabulary in the relatively weaker language.

691 one language but not in the other is not that surprising. Previous work that investigated the 692 relations among measures of the same domain across languages in bilingual children has found 693 similar conclusions. Using measures derived from narrative language samples from Spanish694 English bilingual kindergarteners, Bedore et al. (2010) found cross-language correlations in 695 syntax (Spanish and English MLU in words were significantly correlated) but not in lexical 696 diversity (Spanish and English NDW did not correlate). Pace and colleagues reported a similar 697 pattern where cross-language associations were discovered for syntax but not for vocabulary 698 (Pace et al., 2021). This pattern of relative weakness in vocabulary in one language also 699 resonates with a notion from Parra, Hoff, and Core (2011) that vocabulary is relatively language700 specific because the mapping between a word label and its meaning is unique to each language. 701 Although the interdependence between bilingual children's two languages is not the focus of this 702 paper, the distinct strength/weakness patterns we observed suggest that strength or weakness in 703 one domain in one language does not directly translate to strength in the same domain in the 704 other language. This finding also emphasizes the importance of assessing multiple domains to 705 paint a representative picture of a bilingual child's language abilities. Grade-based Distribution across Four Dual Language Profiles

As illustrated in Figure 4, each language profile included children from kindergarten to 708 third grade. For example, there were some third graders with a Spanish-dominant profile and 
709 some kindergartners with an English-dominant profile. This finding suggests that the variability

710 across observed Spanish and English skills is not solely due to participants' age or years in

711 school. Though this study is limited by a lack of information on the history of participants'

712 language exposure and current language use in their households, it would be interesting for

713 future studies to collect current and past language use data to better understand factors that

714 contribute to different language profiles.

715 Additionally, an interesting pattern that emerged is that the two balanced profiles (Profile

716 1, Balanced-average and Profile 4, Balanced-high) include predominantly children in Grade 3:

$71735 \%$ of children in Profile $1(\mathrm{~N}=230)$ and $43 \%(\mathrm{~N}=78)$ of children in Profile 4 are in grade 3 ,

718 whereas $13 \%(\mathrm{~N}=83)$ of Profile 1 and $10 \%(\mathrm{~N}=9)$ of Profile 4 are kindergartners. The two

719 uneven profiles (Profile 2, Spanish-dominant and Profile 3, English-dominant) demonstrated the

720 inverse grade-based pattern. Specifically, small proportions of third graders were found in the

721 two uneven profiles, $3 \%$ in Profile $2(\mathrm{~N}=2)$ and $13 \%$ in Profile $3(\mathrm{~N}=6)$. The proportional

722 difference in kindergartners and third graders across the four profiles suggests that Spanish-

723 speaking ELs seem to be moving from uneven skills across Spanish and English towards

724 balanced skills across two languages as they get older. This remains a speculation given that the

725 current study used a cross-sectional dataset. We are currently beginning to replicate findings

726 from this study using a longitudinal dataset that followed a group of Spanish-speaking ELs from

727 kindergarten to second grade. If a similar pattern is replicated, such findings would suggest that

728 the transitional bilingual education programs that children in this sample are enrolled in were on

729 the right track to support balanced, dual language development.

$730 \quad$ Practical Implications 
The findings from this study provide implications for both policy and practice. At the

732 policy level, our findings suggest that school districts should consider assessing students'

733 linguistic skills in both languages prior to placement in any particular educational program.

734 Focusing solely on their English skills might not capture their linguistic strengths. The dual

735 language profiles from this study may be used to guide the educational program selection

736 procedure to improve the congruence among students' linguistic needs, teachers' use of

737 instructional language, and the goals of the educational program.

738 At the practice level, our findings suggest that a teacher in a transitional bilingual

739 program may encounter a mixed group of bilingual children with drastically different linguistic

740 abilities across domains and languages. Although alternative programs or classrooms might not

741 be available in all school districts, the language profiles emerged from this study could provide

742 teachers and other professionals (e.g., speech-language pathologists, special educators) guidance

743 as to the best instructional approach to address the linguistic needs of their students. For

744 example, educators who work with bilingual children with different language profiles may

745 intentionally use linguistically responsive teaching strategies, such as learning about students'

746 linguistic backgrounds, identifying content-specific language demands, and providing

747 comprehensible instructional input based on student's language profiles (Krashen, 2003; Solano-

748 Campos et al., 2020). School-based teams may also collaborate to monitor the progress made by

749 students with different profiles in oral language in one or both languages across different

750 educational contexts across the school year to inform instruction.

751 Limitations and Future Directions

752 Findings from this study should be interpreted in light of the following limitations. Of the

7531,532 children tested as part of the larger project, 595 children were excluded because either the 
754 English or the Spanish sample was missing. There are various reasons why these samples could

755 be missing: the child was absent during the test date; the child refused to do the task; or the child

756 did not have the linguistic skills to do the task. The number of participants eliminated from the

757 original pool varied by grades, with the largest number of children excluded being kindergartners

758 and first graders: 158 kindergartners and 112 first graders were excluded because of missing

759 English samples. We are cognizant that eliminating close to one-third of the original pool,

760 especially younger children who were disproportionately missing English samples, could

761 introduce sampling bias and limit the external validity of our findings. Because of these missing

762 data, we want to emphasize that the language profiles identified in this study were based on a

763 truncated sample of English learners and may not generalize to represent EL students who

764 function essentially as monolingual Spanish speakers with negligible English skills. Likewise, a

765 group of children with low language skills in both Spanish and English was also not represented

766 in this sample. It is critical that future studies examine language abilities, profiles, and

767 longitudinal development in children with low language skills in both languages. For example,

768 future studies that include bilingual children with a broader range of language proficiency may

769 include a measure of grammaticality to verify the dual language profiles emerged from this study

770 and to identify additional dual language profiles.

771 Given that this study used a cross-sectional dataset, future studies should examine

772 longitudinal language profiles in Spanish-speaking EL students to (a) investigate the stability of

773 the distinct language profiles identified in this study over time, (b) examine the potential shifting

774 of children from one language profile to another profile, (c) identify new profiles that may

775 longitudinally emerge that would not be captured by this dataset, and (d) understand long-term

776 academic outcomes, such as literacy, of the students in different profiles. 
Lastly, all participants in this study were enrolled in transitional bilingual programs

778 where the instructional language gradually shifted from Spanish to English through third grade. A recent study has shown that Spanish-English bilingual children in English-immersion programs demonstrated loss of Spanish syntactic and vocabulary skills (Hiebert \& Rojas, 2021). Such findings suggest that Spanish-English bilingual students in transitional bilingual programs and English-focused programs may show different growth trajectories in Spanish and English across grades and thus may display different dual language profiles. Future studies that examine dual language profiles in students in English-focused programs would help us gain a clearer picture on the extent to which the educational program impacts dual language profiles in Spanish-English bilingual students. Related, another area of future research is to examine gains in oral language in one or both languages in students with different language profiles in transitional bilingual programs vs. English-focused programs to facilitate program assignment and optimize instruction for different students.

\section{Conclusions}

In sum, this study extends the current bilingual literature by demonstrating large variability in both Spanish and English oral language skills in a Spanish-speaking ELs, a subgroup of bilingual children often considered and treated as homogenous. Four distinct latent dual language profiles emerged, including an English-dominant group. Children in different dual language profiles also displayed distinct patterns of unique strength or weakness in specific language domains. Future work could test the replicability of the dual language profiles discovered in this study in a different subgroup of bilingual children (e.g., bilingual children designated as English proficient students), extend these findings in additional educational contexts (e.g., ELs in a different educational program), and examined the stability of dual 
800 language profiles across grades. Refinements of the empirically based dual language profiles

801 may facilitate the educational program placement procedure for bilingual children to precisely

802 identify educational programs best suited for children's linguistic needs. For researchers, the dual

803 language profiles emerged may also be used to guide participant selection process to create better 804 defined samples of bilingual children.

805 
808 (jointly funded by the National Institute of Child Health and Human Development, and the 809 Institute of Education Sciences). 


\section{Data Availability Statement (DAS)}

811 The datasets generated during and/or analyzed during the current study are available from

812 the corresponding author on reasonable request.

813 


\section{References}

815 Alt, M., Arizmendi, G. D., \& DiLallo, J. N. (2016). The role of socioeconomic status in the narrative story retells of school-aged English language learners. Language, Speech, and Hearing Services in Schools, 47(4), 313-323. https://doi.org/10.1044/2016_LSHSS-15-

Barrow, L., \& Markman-Pithers, L. (2016). Supporting young English learners in the United 0036

Berlin, K. S., Williams, N. A., \& Parra, G. R. (2014). An introduction to latent variable mixture modeling (part 1): Overview and cross-sectional latent class and latent profile analyses. States. The Future of Children, 26(2), 159-183.

Bedore, L., Peña, E. D., Gillam, R. B., \& Ho, T. H. (2010). Language sample measures and language ability in Spanish-English bilingual kindergarteners. Journal of Communication Disorders, 43(6), 498-510. https://doi.org/10.1016/j.jcomdis.2010.05.002 Journal of pediatric psychology, 39(2), 174-187.

Bitetti, D., \& Hammer, C. S. (2021). English narrative macrostructure development of spanishenglish bilingual children from preschool to first grade. American Journal of SpeechLanguage Pathology,30(3), 1100-1115. https://doi.org/10.1044/2021_AJSLP-20-00046

833 Blom, E., Boerma, T., Bosma, E., Cornips, L., van den Heuij, K., \& Timmermeister, M. (2020). Cross-language distance influences receptive vocabulary outcomes of bilingual children. First Language, 40(2), 151-171. https://doi.org/10.1177/0142723719892794

Bitetti, D., Hammer, C. S., \& López, L. M. (2020). The narrative macrostructure production of Spanish-English bilingual preschoolers: Within- and cross-language relations. Applied Psycholinguistics, 41(1), 79-106. https://doi.org/10.1017/S0142716419000419 First Language, 40(2), 151-171. https.//doi.org/10.1177/0142723719892794 Boyle, A., August, D., Tabaku, L., Cole, S., \& Simpson-Baird, A. (2015). Dual language 
education programs: Current state policies and practices. Office of English Language Acquisition, US Department of Education.

839 Cain, M. K., Zhang, Z., \& Yuan, K. H. (2017). Univariate and multivariate skewness and kurtosis for measuring nonnormality: Prevalence, influence and estimation. Behavior Research Methods, 49(5), 1716-1735. https://doi.org/10.3758/s13428-016-0814-1

Calderón, M., Slavin, R., \& Sánchez, M. (2011). Effective instruction for English learners. Future of Children, 21(1), 103-127. https://doi.org/10.1353/foc.2011.0007

Castilla-Earls, A., Bedore, L., Rojas, R., Fabiano-Smith, L., Pruitt-Lord, S., Restrepo, M. A., \& Peña, E. D. (2020). Beyond scores: Using converging evidence to determine speech and language services eligibility for dual language learners. American Journal of Speech-

851 Castilla-Earls, A., Francis, D. J., Iglesias, A., \& Davidson, K. (2019). The impact of the Spanishto-English proficiency shift on the grammaticality of English Learners. Journal of Language Pathology,29(3), 1116-1132. https://doi.org/10.1044/2020_AJSLP-19-00179

Castilla-Earls, A., \& Eriks-Brophy, A. (2012). Spontaneous language measures in monolingual preschool Spanish-speaking children. Revista de Logopedia, Foniatría y Audiología, 32(3), 97-108. https://doi.org/10.1016/J.RLFA.2012.04.001 Speech, Language, and Hearing Research : JSLHR, 62(6), 1739-1754. https://doi.org/10.1044/2018_JSLHR-L-18-0324

Conti-Ramsden, G., Crutehley, A., \& Botting, N. (1997). The extent to which psychometric children with SLI. Journal of Speech, Language, and Hearing Research, 40(4), 765-777. https://doi.org/10.1044/jslhr.4004.765

Covington, M. A., \& McFall, J. D. (2010). Cutting the gordian knot: The moving-average typetoken ratio (MATTR). Journal of Quantitative Linguistics, 17(2), 94-100. 

https://doi.org/10.1080/09296171003643098

861 Cummins, J., \& Mulcahy, R. (1978). Orientation to language in Ukrainian-English bilingual children. Child Development, 49(4), 1239. https://doi.org/10.2307/1128769

DeAvila, E. A., \& Duncan, S. E. (2000). PreLAS2000: English and Spanish technical notes. Monterey, CA: CTB/McGraw-Hill.

De Houwer, A. (2007). Parental language input patterns and children's bilingual use. Applied Psycholinguistics, 28(3), 411-424. https://doi.org/10.1017/S0142716407070221

Dunn, L. M., \& Dunn, D. M. (2007). PPVT-4: Peabody picture vocabulary test. Bloomington: Pearson Assessments.

Ebert, K. D. (2020). Language sample analysis with bilingual children: Translating research to practice. Topics in Language Disorders, 40(2), 182-201. https://doi.org/10.1097/TLD.0000000000000209

Espinosa, L. M. (2015). Challenges and benefits of early Bilingualism in the U.S. context.

874 Fergadiotis, G., Wright, H. H., \& Green, S. B. (2015). Psychometric evaluation of lexical diversity indices: Assessing length effects. Journal of Speech, Language, and Hearing

Fergadiotis, G., Wright, H. H., \& West, T. M. (2013). Measuring lexical diversity in narrative Global Education Review, 2(1), 40-53.

Fiestas, C. E., \& Peña, E. D. (2004). Narrative discourse in bilingual children: Language and task effects. Language, Speech, and Hearing Services in Schools, 35(2), 155-168. https://doi.org/10.1044/0161-1461(2004/016) 
883 Floccia, C., Sambrook, T. D., Delle Luche, C., Kwok, R., Goslin, J., White, L., Cattani, A.,

884

885

886

887

\section{8}

889

890

891

892

893

894

895

896

897

898

899

900

901

902

903

904

905
Sullivan, E., Abbot-Smith, K., Krott, A., Mills, D., Rowland, C., Gervain, J., Plunkett, K., Hoff, E., Core, C., \& Patricia, J. (2018). Vocabulary of 2-year-olds learning English and an additional language: Norms and effects of linguistic distance. Monographs of the Society for Research in Child Development, 83(1), 7-29.

Francis, D. J., Carlson, C., Fletcher, J., Foorman, B., Goldenberg, C., Vaughn, S., \& Papanicolaou, A. (2005). Oracy/literacy development of Spanish-speaking chil-dren: A multi-level program of research on language minority children and theinstruction, school and community contexts, and interventions that influence their academic outcomes. Perspectives: The International Dyslexia Association, 31, 8-12.

García, O., Flores, N., \& Chu, H. (2011). Extending bilingualism in U.S. secondary education: New variations. International Multilingual Research Journal, 5(1), 1-18. https://doi.org/10.1080/19313152.2011.539486

Genesee, F., Nicoladis, E., \& Paradis, J. (1995). Language differentiation in early bilingual development. Journal of Child Language, 22(3), 611-631. https://doi.org/10.1017/S0305000900009971

Genesee, F., Paradis, J., \& Crago, M. B. (2004). Dual language development \& disorders: A handbook on bilingualism \& second language learning. Paul H Brookes Publishing.

Gonzalez, J., Pollard-Durodola, S., Saenz, L., Soares, D., Davis, H., Resendez, N., \& Zhu, L. (2016). Spanish and English early literacy profiles of preschool Latino English language learner children. Early Education and Development, 27(4), 513-531. https://doi.org/10.1080/10409289.2015.1077038

Grimm, R. P., Solari, E. J., Gerber, M. M., Nylund-Gibson, K., \& Lee Swanson, H. (2019). A 
SPANISH-ENGLISH DUAL LANGUAGE PROFILES

906

907

908

909

910

911

912

913

914

915

916

917

918

919

920

921

922

923

924

925

926

927

928

cross-linguistic examination of heterogeneous reading profiles of spanish-speaking bilingual students. Elementary School Journal, 120(1), 109-131.

https://doi.org/10.1086/704514

Gutiérrez-Clellen, V. F. (1998). Syntactic skills of Spanish-speaking children with low school achievement. Language Speech and Hearing Services in Schools, 29(4), 207-215.

Gutiérrez-Clellen, V. F. (1999). Language choice in intervention with bilingual children. American Journal of Speech-Language Pathology, 8(4), 291-302. https://doi.org/10.1044/1058-0360.0804.291

Gutiérrez-Clellen, V. F. (2002). Narratives in two languages: Assessing performance of bilingual children. Linguistics and Education, 13(2), 175-197. https://doi.org/10.1016/S0898$5898(01) 00061-4$

Gutiérrez-Clellen, V. F., \& Hofstetter, R. (1994). Syntactic complexity in Spanish narratives: A developmental study. Journal of Speech and Hearing Research, 37(3), 645-654. https://doi.org/10.1044/jshr.3703.645

Gutiérrez-Clellen, V. F., Restrepo, M. A., Bedore, L., Peña, E. D., \& Anderson, R. (2000). Language sample analysis in Spanish-speaking c hildren. Language, Speech, and Hearing Services in Schools, 31(1), 88-98. https://doi.org/10.1044/0161-1461.3101.88

Halpin, E., Prishker, N., \& Melzi, G. (2021). The bilingual language diversity of Latino Preschoolers: A latent profile analysis. Language, Speech, and Hearing Services in Schools, 1-12.

Heilmann, J. J., Miller, J. F., Iglesias, A., Fabiano-Smith, L., Nockerts, A., \& Andriacchi, K. D. (2008). Narrative transcription accuracy and reliability in two languages. Topics in Language Disorders, 28(2), 178-188. 
https://doi.org/10.1097/01.TLD.0000318937.39301.76

930

931

932

933

934

935

936

937

938

939

940

941

942

943

944

945

946

947

948

949

950

951

Heilmann, J. J., Miller, J. F., Nockerts, A., \& Dunaway, C. (2010). Properties of the narrative scoring scheme using narrative retells in young school-Age children. American Journal of Speech-Language Pathology, 19(2), 154-166. https://doi.org/10.1044/10580360(2009/08-0024)

Heilmann, J. J., Rojas, R., Iglesias, A., \& Miller, J. F. (2016). Clinical impact of wordless picture storybooks on bilingual narrative language production: A comparison of the "Frog" stories. International Journal of Language and Communication Disorders, 51(3), 339345. https://doi.org/10.1111/1460-6984.12201

Hernandez, D. J., Denton, N. A., \& Macartney, S. E. (2008). Children in immigrant families: Looking to America's future. Social Policy Report, 22(3), 1-24. https://doi.org/10.1002/j.2379-3988.2008.tb00056.x

Hiebert, L., \& Rojas, R. (2021). A longitudinal study of Spanish language growth and loss in young Spanish-English bilingual children. Journal of Communication Disorders, 92, 106110. https://doi.org/10.1016/j.jcomdis.2021.106110

Hipp, J. R., \& Bauer, D. J. (2006). Local solutions in the estimation of growth mixture models. Psychological methods, 11(1), 36.

Hoff, E. (2013). Interpreting the early language trajectories of children from low-SES and language minority homes: implications for closing achievement gaps. Developmental Psychology, 49(1), 4-14. https://doi.org/10.1037/a0027238

Hoff, E., \& Core, C. (2015). What clinicians need to know about bilingual development. Seminars in Speech and Language, 36(2), 089-099. https://doi.org/10.1055/s-00351549104 
952 Hoff, E., Core, C., Place, S., Rumiche, R., Señor, M., \& Parra, M. (2012). Dual language

953 exposure and early bilingual development. Journal of Child Language, 39(1), 1-27.

954 https://doi.org/10.1017/S0305000910000759

955 Kapantzoglou, M., Fergadiotis, G., \& Buenavides, A. A. (2019). Psychometric evaluation of

956 lexical diversity indices in Spanish narrative samples from children with and without

957 developmental language disorder. Journal of Speech, Language, and Hearing Research,

958 62(1), 70-83.https://doi.org/10.1044/2018_JSLHR-L-18-0110

959 Kapantzoglou, M., Restrepo, M. A., Gray, S., \& Thompson, M. S. (2015). Language ability

960

961 groups in bilingual children: A latent profile analysis. Journal of Speech, Language, and Hearing Research, 58(5), 1549-1562. https://doi.org/10.1044/2015_JSLHR-L-14-0290

Kieffer, M. J. (2012). Early oral language and later reading development in Spanish-speaking English language learners: Evidence from a nine-year longitudinal study. Journal of Applied Developmental Psychology, 33(3), 146-157.

Klingner, J. K., Boardman, A. G., Eppolito, A. M., \& Schonewise, E. A. (2012). Supporting https://doi.org/10.1016/j.appdev.2012.02.003

Krashen, S. D. (2003). Current Issues and Controversies: Does Grammar Teaching Work? What About "Comprehensible Output"? In Explorations in language acquisition and use (pp. 30-65). Heinemann.

972 Krippendorff, K. (2011). Computing Krippendorff' s alpha reliability. Departmental Papers $973 \quad(A S C), 12$.

974 Landry, S. H., Swank, P. R., Assel, M. A., \& King, T. (2009). The CIRCLE phonological 
SPANISH-ENGLISH DUAL LANGUAGE PROFILES

975

976

977

978

979

980

981

982

983

984

985

986

987

988

989

990

991

992

993

994

995

996

997

awareness, language, and literacy system (C-PALLS): Technical manual. Children's Learning Institute. Unpublished research.

Linquanti, R., Cook, H. G., Bailey, A. L., \& MacDonald, R. (2016). Moving toward a more common definition of English Learner : Collected guidance for states and multi-state assessment consortia (Issue January). Council of Chief State School Officers.

Lo, Y., Mendell, N., \& Rubin, D. (2001). Testing the number of components in a normal mixture. Biometrika, 88(3).

Lonigan, C. J., Goodrich, J. M., \& Farver, J. A. M. (2018). Identifying differences in early literacy skills across subgroups of language-minority children: A latent profile analysis. Developmental Psychology, 54(4), 631-647. https://doi.org/10.1037/dev0000477

López, L. M., \& Foster, M. E. (2021). Examining heterogeneity among Latino dual language learners' school readiness profiles of English and Spanish at the end of Head Start. Journal of Applied Developmental Psychology, 73(January). https://doi.org/10.1016/j.appdev.2021.101239

Lubke, G. H., \& Muthén, B. O. (2005). Investigating population heterogeneity with factor mixture models. Psychological Methods, 10(1), 21-39. https://doi.org/10.1037/1082989X.10.1.21

Lucero, A. (2015). Cross-linguistic lexical, grammatical, and discourse performance on oral narrative retells among young Spanish speakers. Child Development, 86(5), 1419-1433. https://doi.org/10.1111/cdev.12387

Masyn, K. E. (2013). Latent class analysis and finite mixture model. In The Oxford Handbook of Quantitative Methods (Vol. 2, pp. 551-611).

May, S. (2008). Bilingual/immersion education: What the research tells us. Encyclopedia of 
998

999

1000

1001

1002

1003

1004

1005

1006

1007

1008

1009

1010

1011

1012

1013

1014

1015

1016

1017

1018

1019

Language and Education, 5(1), 19-34.

Mayer, M. (1969) Frog where are you? New York: Dial Press.

Méndez, L. I., Perry, J., Holt, Y., Bian, H., \& Fafulas, S. (2018). Same or different: Narrative retells in bilingual Latino kindergarten children. Bilingual Research Journal, 41(2), 150166. https://doi.org/10.1080/15235882.2018.1456984

Miller, J. F., Andriacchi, K., \& Nockerts, A. (2015a). Monolingual Spanish story retell database. In Assessing Language Production Using SALT Software: A Clinician's Guide to Language Sample Analysis (Second Edi). SALT Software, LLC.

Miller, J. F., Andriacchi, K., \& Nockerts, A. (2015b). Narrative story retell database. In Assessing Language Production Using SALT Software: A Clinician's Guide to Language Sample Analysis (Second Edi). SALT Software, LLC.

Miller, J. F., Heilmann, J. J., Nockerts, A., Iglesias, A., Fabiano, L., \& Francis, D. J. (2006). Oral language and reading in bilingual children. Learning Disabilities Research and Practice, 21(1), 30-43. https://doi.org/10.1111/j.1540-5826.2006.00205.x

Miller, J. \& Iglesias, A. (2019). Systematic Analysis of Language Transcripts (SALT), Research Version 20 [Computer Software]. Madison, WI: SALT Software, LLC. https://www.saltsoftware.com/products/software

Muthén, B. O. (2003). Statistical and substantive checking in growth mixture modeling: Comment on Bauer and Curran (2003). Psychological Methods, 8(3), 369-377. https://doi.org/10.1037/1082-989X.8.3.369

Muthén, B. O. (2004). Latent variable analysis. In The Sage handbook of quantitative methodology for the social sciences (pp. 345-368). Sage. 
1020 Muthén, L.K. and Muthén, B.O. (1998-2017). Mplus User’s Guide. Eighth Edition. Los 1021 Angeles, CA: Muthén \& Muthén.

1022 Nagin, D. S. (2005). Group-based modeling of development. Cambridge: Harvard University $1023 \quad$ Press.

1024 National Research Council. (2011). Allocating federal funds for state programs for English $1025 \quad$ language learners. National Academies Press.

1026 Nevada Administrative Code $§ 388.630$, (2018).

1027 Nylund-Gibson, K., \& Choi, A. Y. (2018). Ten frequently asked questions about latent class 1028 analysis. Translational Issues in Psychological Science, 4(4), 440-461. https://doi.org/10.1037/tps0000176

Nylund, K. L., Asparouhov, T., \& Muthén, B. O. (2007). Deciding on the number of classes in latent class analysis and growth mixture modeling: A Monte Carlo simulation study. Structural Equation Modeling, 14(4), 535-569.

1034 Office of English Language Acquisition [OELA]. (2019). English Learners and Instructional 1035 Programs.

1036 Pace, A., Luo, R., Levine, D., Iglesias, A., de Villiers, J., Golinkoff, R., Wilson, M. S., \& Hirsh1037 Pasek, K. (2021). Within and across language predictors of word learning processes in 1038 dual language learners. Child Development, 92(1), 35-53.

1039 https://doi.org/10.1111/cdev.13418

1040 Paradis, J., \& Genesee, F. (1996). Syntactic acquisition in bilingual children: Autonomous or 1041 interdependent? Studies in Second Language Acquisition, 18(1), 1-25. https://doi.org/10.1017/S0272263100014662 
1043 Parra, M., Hoff, E., \& Core, C. (2011). Relations among language exposure, phonological

1044

1045

1046

1047

1048

1049

1050

1051

1052

1053

1054

1055

1056

1057

1058

1059

1060

1061

1062

1063

1064

1065

memory, and language development in Spanish-English bilingually developing 2-yearolds. Journal of Experimental Child Psychology, 108(1), 113-125. https://doi.org/10.1016/j.jecp.2010.07.011

Pastor, D. A., Barron, K. E., Miller, B. J., \& Davis, S. L. (2007). A latent profile analysis of college students' achievement goal orientation. Contemporary Educational Psychology, 32(1), 8-47. https://doi.org/10.1016/j.cedpsych.2006.10.003

Peña, E. D., Gillam, R. B., Malek, M., Ruiz-Felter, R., Resendiz, M., Fiestas, C., \& Sabel, T. (2006). Dynamic assessment of school-age children's narrative ability: An experimental investigation of classification accuracy. Journal of Speech, Language, and Hearing Research, 49(5), 1037-1057. https://doi.org/10.1044/1092-4388(2006/074)

Peña, E. D., Gutiérrez-Clellen, V. F., Iglesias, A., Goldstein, B. A., \& Bedore, L. (2014). Bilingual English-Spanish Assessment (BESA). AR-Clinical Publications. Clinical Publications.

Pornprasertmanit, S., Lee, J., \& Preacher, K. J. (2014). Ignoring clustering in confirmatory factor analysis: Some consequences for model fit and standardized parameter estimates. Multivariate Behavioral Research, 49(6), 518-543. https://doi.org/10.1080/00273171.2014.933762

Ramaswamy, V., Desarbo, W. S., Reibstein, D. J., \& Robinson, W. T. (1993). An empirical pooling approach fur estimating marketing mix elasticities with PIMS data. Marketing Science, 12(1), 103-124.

Restrepo, M. A., Gorin, J., \& Gray, S. (2013). Spanish Screener for Language Impairment in Children (SSLIC). Manuscrito no publicado, Department of Communication Sciences, 
1066

1067

1068

1069

1070

1071

1072

1073

1074

1075

1076

1077

1078

1079

1080

1081

1082

1083

1084

1085

1086

1087

1088

Arizona State University, Chandler, AZ, Estados Unidos.

Riggenrach, H. (1991). Toward an understanding of fluency: A microanalysis of nonnative speaker conversations. Discourse Processes, 14(4), 423-441.

https://doi.org/10.1080/01638539109544795

Rojas, R., Hiebert, L., Gusewski, S., \& Francis, D. J. (2019). Moving forward by looking back: Understanding why some Spanish-speaking English Learners fall behind. New Directions for Child and Adolescent Development, 2019(166), 43-77. https://doi.org/10.1002/cad.20305

Rojas, R., \& Iglesias, A. (2006). Bilingual (Spanish-English) Narrative Language Analyses: Why and How? Perspectives on Communication Disorders and Sciences in Culturally and Linguistically Diverse (CLD) Populations, 13(1), 3-8. https://doi.org/10.1044/cds13.1.3

Rojas, R., \& Iglesias, A. (2013). The language growth of Spanish-speaking English Language Learners. Child Development, 84(2), 630-646. https://doi.org/10.1111/j.14678624.2012.01871.x

Scott, C. M., \& Stokes, S. L. (1995). Measures of syntax in school-age children and adolescents. Language, Speech, and Hearing Services in Schools, 26(4), 309-319. https://doi.org/10.1044/0161-1461.2604.309

Serratrice, L. (2013). Cross-linguistic influence in bilingual development: Determinants and mechanisms. Linguistic Approaches to Bilingualism, 3(1), 3-25. https://doi.org/10.1075/LAB.3.1.01SER

Slavin, R. E., \& Cheung, A. (2005). A synthesis of research on language of reading instruction for English language learners. Review of Educational Research, 75(2), 247-284. https://doi.org/10.3102/00346543075002247 
1089 Solano-Campos, A., Hopkins, M., \& Quaynor, L. (2020). Linguistically Responsive Teaching in

1090

1091

1092

1093

1094

1095

1096

1097

1098

1099

1100

1101

1102

1103

1104

1105

1106

1107

1108

1109

1110

1111
Preservice Teacher Education: A Review of the Literature Through the Lens of CulturalHistorical Activity Theory. Journal of Teacher Education, 71(2), 203-217. https://doi.org/10.1177/0022487118808785

Tabachnick, B. G., \& Fidell, L. S. (2012). Using multivariate statistics (6th ed.). In New York: Harper and Row. https://doi.org/10.1037/022267

Tanenbaum, C., Boyle, A., Soga, K., Carlson Le Floch, K., Golden, L., Petroccia, M., Toplitz, M., Taylor, J., \& O’Day, J. (2012). National evaluation of Title III implementation: Report on state and local implementation. In U.S. Department of Education Office of Planning, Evaluation and Policy Development Policy and Program Studies Service: Vol. №3.

Thorndike, R. L., Hagan, E. P., \& Sattler, J. M. (1986). Stanford-Binet Intelligence Scale, Fourth Edition. Chicago: Riverside.

Tomblin, J. B., \& Zhang, X. (2006). The dimensionality of language ability in school-age children. Journal of Speech, Language, and Hearing Research, 49, 1193-1208. https://doi.org/10.1136/bmj.1.3191.317-a

U.S. Census Bureau. (2015). Educational Attainment of the Population 18 Years and Over, by Age, Sex, Race, and Hispanic Origin: 2015. https://www.census.gov/data/tables/2015/demo/education-attainment/p20-578.html

U.S. Department of Education. (2006). The Condition of Education 2006 (NCES 2006-071). https://nces.ed.gov/pubs2006/2006071.pdf

U.S. Department of Education, Office for Civil Rights, \& U.S. Department of Justice. (2015). Dear colleague letter, English learner students and limited English proficient parents 
1113 Unsworth, S. (2016). Quantity and quality of language input in bilingual language development.

1114 In Bilingualism across the lifespan (pp. 103-121). American Psychological Association.

1115 Vermunt, J., \& Magidson, J. (2002). Latent Class Cluster Analysis. In J. Hagenaars \& A.

1116 McCutcheon (Eds.),. In H. \& A. McCutcheon (Ed.), Applied Latent Class Analysis (pp.

1117 89-106). Cambridge: Cambridge University Press.

1118 https://doi.org/doi:10.1017/CBO9780511499531.004

1119 Williams KT. Expressive Vocabulary Test, Second Edition (EVT-2). Minneapolis, MN: Pearson $1120 \quad$ Assessments; 2007.

1121 Wechsler, D., \& Naglieri, J. A. (2006). Wechsler Nonverbal Scale of Ability (WNV). APA

1122 PsycTests. https://doi-org.udel.idm.oclc.org/10.1037/t15176-000

1123 Woodcock, R., McGrew, K., \& Mather, N. (2001). Woodcock-Johnson tests of achievement -

1124 Third Edition. Itasca, IL: Riverside Publishing.

1125 Woo, S. E., Jebb, A. T., Tay, L., \& Parrigon, S. (2018). Putting the "person” in the center:

1126 Review and synthesis of person-centered approaches and methods in organizational

1127 science. Organizational Research Methods, 21(4), 814-845.

1128 https://doi.org/10.1177/1094428117752467

1129 Zimmerman, I. L., Steiner, V. G., \& Pond, R. E. (2002). Preschool Language Scale, Fourth

1130 Edition. San Antonio, TX: Psychological Corporation. 
1134 Figure 1. Information Criteria Indices (SABIC, CAIC, and AWE) Values for all Estimated LPA

1135 Models. Note: Dashed lines correspond to the index value of the minimum-goodness-of-fit

1136 benchmark model (Model C1 - One-profile model with class-invariant, unrestricted $\boldsymbol{\Sigma}_{\mathbf{k}}$ ).

1138 Figure 2. Students' Performance on English and Spanish Oral Language Measures as a Function 1139 of Latent Profile. Note: Profile 1 = Balanced-average; Profile 2 = Spanish-dominant; Profile $3=$ 1140 English-dominant; Profile $4=$ Balanced-high. SI = subordination index; MATTR = moving1141 average type-token ratio; NSS = narrative structure scheme; WPM = words per minute.

1143 Figure 3. Comparison of Students' Performance on English (Blue) and Spanish (Red) as a 1144 Function of Latent Profile. Note: Profile 1 = Balanced-average; Profile 2 = Spanish-dominant; 1145 Profile 3 = English-dominant; Profile $4=$ Balanced-high. SI = subordination index; MATTR = 1146 moving-average type-token ratio; NSS = narrative structure scheme; WPM = words per minute.

1148 Figure 4. Grade Distribution (K-3) as a Function of Latent Profile. Note: Profile 1 = Balanced1149 average; Profile 2 = Spanish-dominant; Profile 3 = English-dominant; Profile 4 = Balanced-high.

1151 Figure 5. Mean Comparison of English and Spanish Oral Language Abilities between children in

1152 Profile 4 and Sex-, Grade-, Length-Matched Samples from SALT Monolingual English-

1153 Speaking Norm and Monolingual Spanish-Speaking Norm. Note: Profile $4=$ Balanced-high. ${ }^{* *} p$ $1154<.01,{ }^{* * *} p<.001$. 

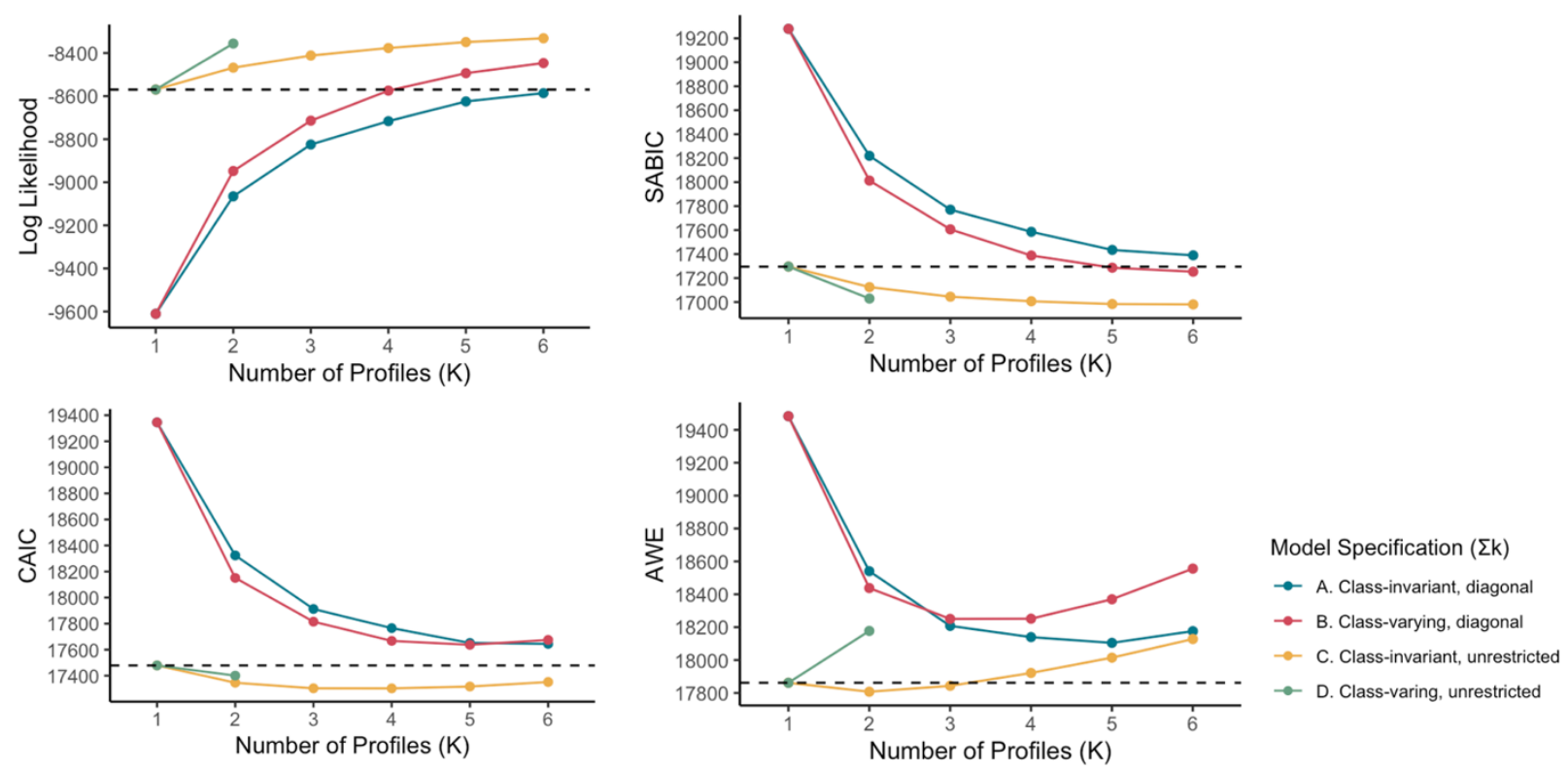

Figure 1. Information Criteria Indices (SABIC, CAIC, and AWE) Values for all Estimated LPA Models. Note: Dashed lines correspond to the index value of the minimum-goodness-of-fit benchmark model (Model C1 - One-profile model with class-invariant, unrestricted $\boldsymbol{\Sigma}_{\mathbf{k}}$ ). 


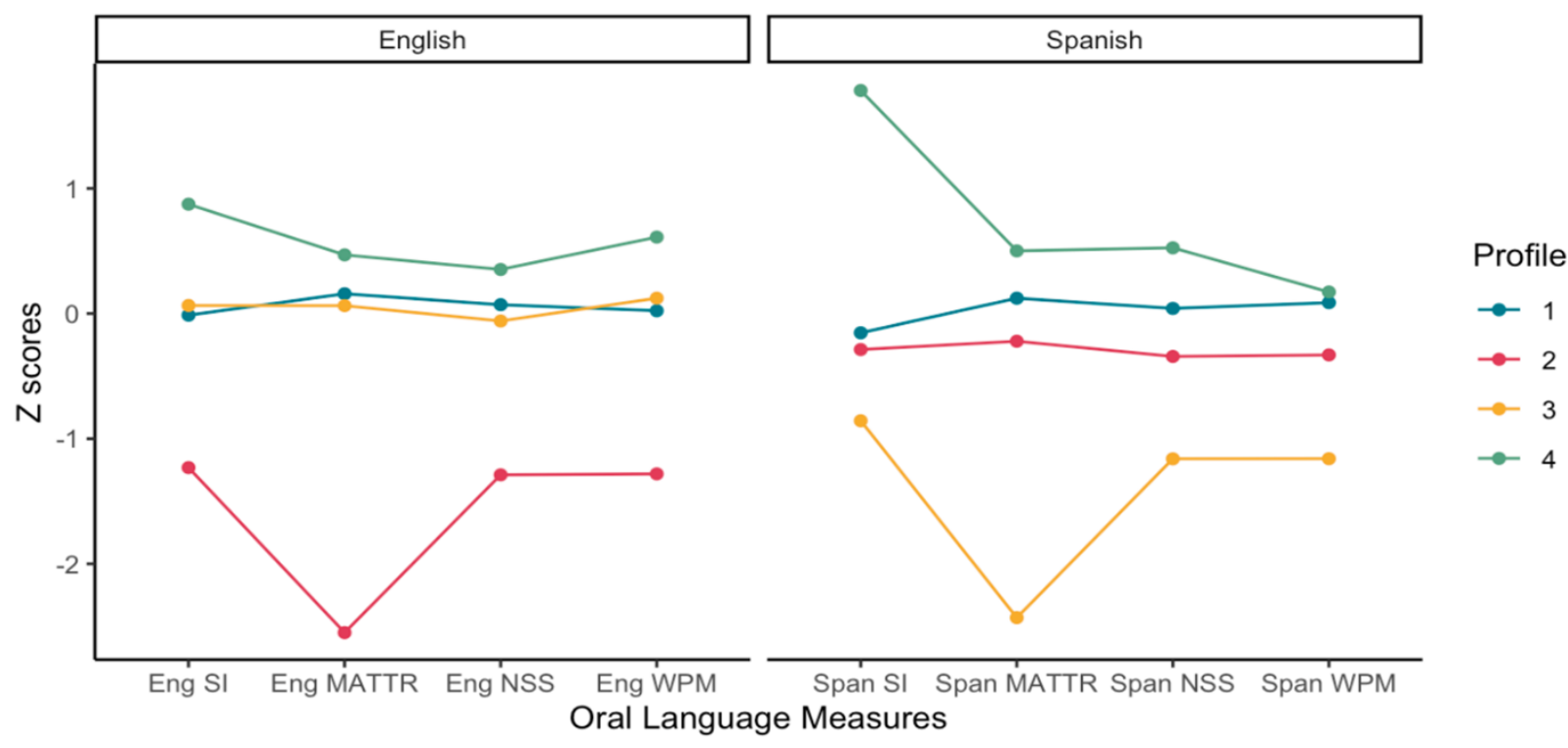

Figure 2. Students' Performance on English and Spanish Oral Language Measures as a Function of Latent Profile. Note: Profile 1 = Balanced-average; Profile 2 = Spanish-dominant; Profile $3=$ English-dominant; Profile 4 = Balanced-high. SI = subordination index; MATTR = movingaverage type-token ratio; NSS = narrative structure scheme; WPM = words per minute. 


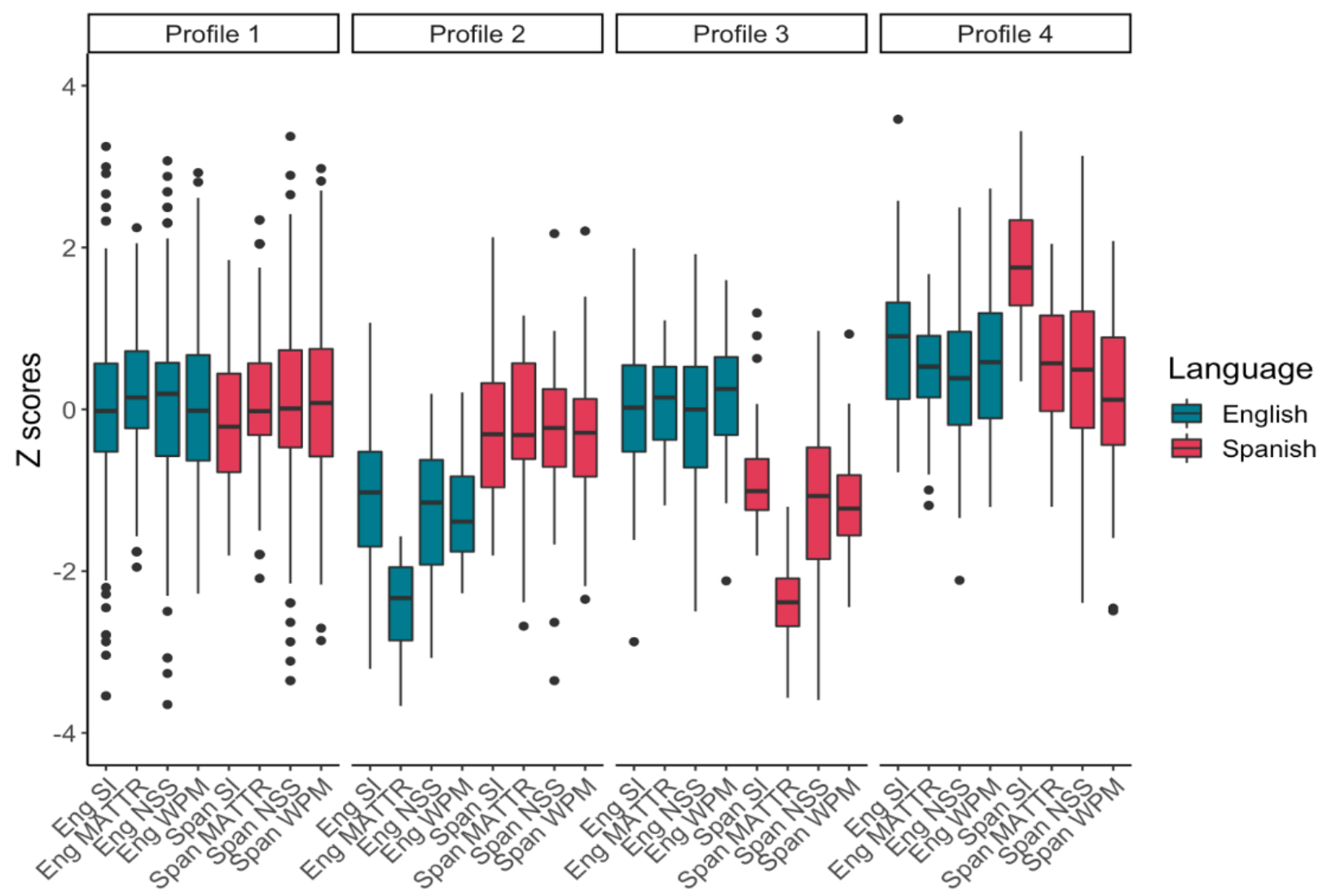

Figure 3. Comparison of Students' Performance on English (Blue) and Spanish (Red) as a Function of Latent Profile. Note: Profile 1 = Balanced-average; Profile 2 = Spanish-dominant; Profile 3 = English-dominant; Profile $4=$ Balanced-high. SI $=$ subordination index; MATTR $=$ moving-average type-token ratio; NSS = narrative structure scheme; WPM = words per minute. 


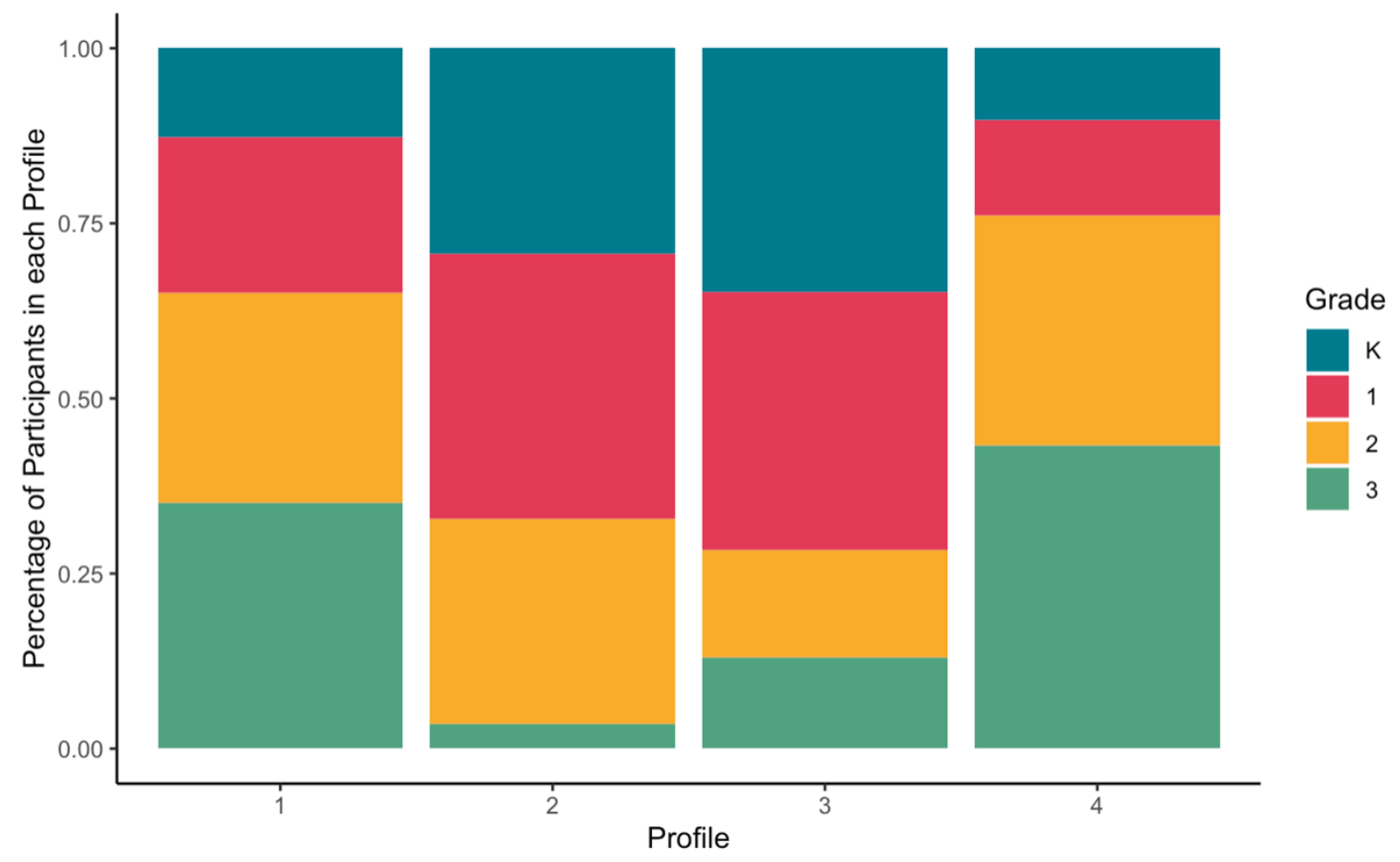

Figure 4. Grade Distribution (K-3) as a Function of Latent Profile. Note: Profile $1=$ Balancedaverage; Profile 2 = Spanish-dominant; Profile 3 = English-dominant; Profile 4 = Balanced-high . 


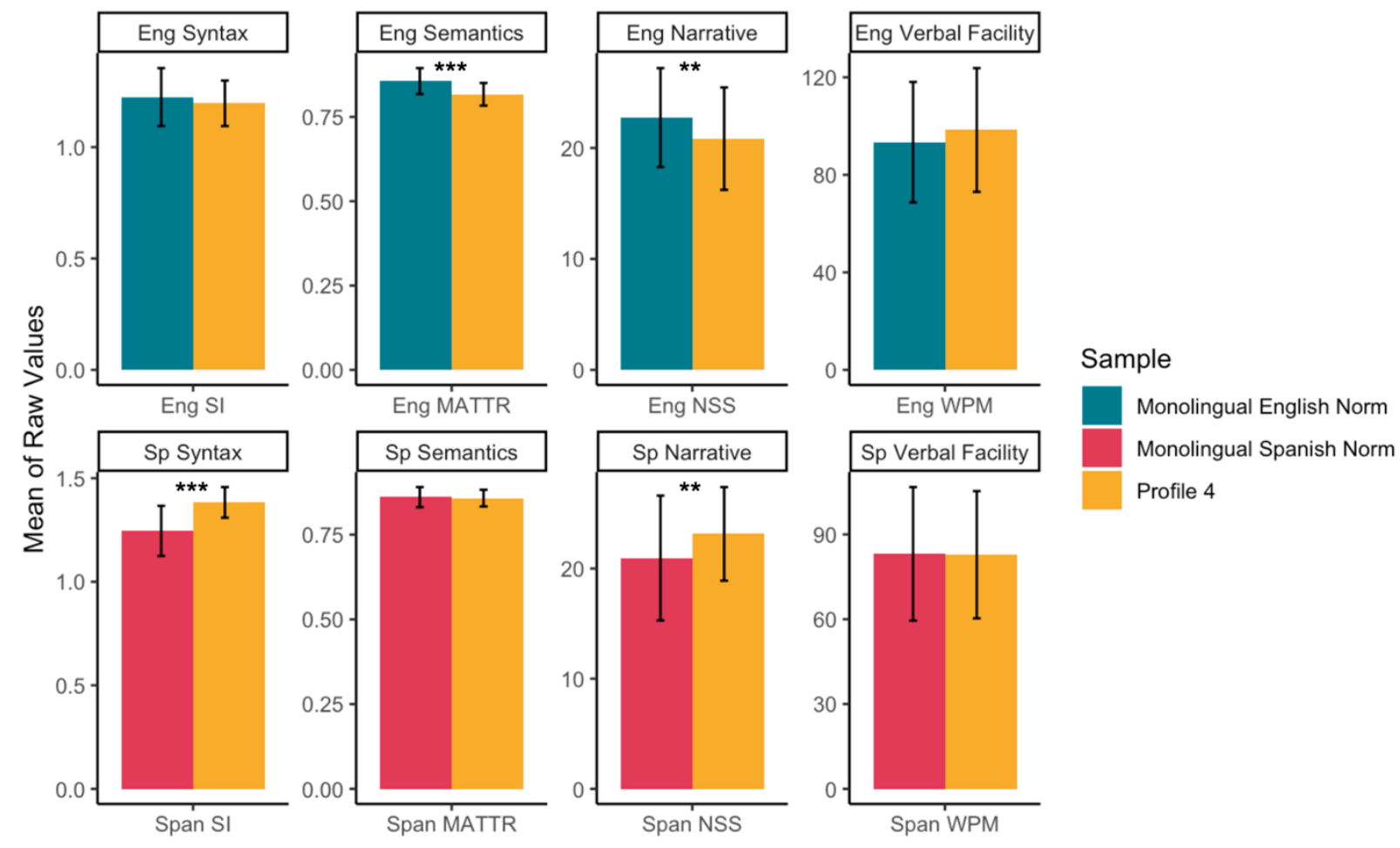

Figure 5. Mean Comparison of English and Spanish Oral Language Abilities between children in Profile 4 and Sex-, Grade-, Length-Matched Samples from SALT Monolingual EnglishSpeaking Norm and Monolingual Spanish-Speaking Norm. Note: Profile $4=$ Balanced-high. ${ }^{* *} p$ $<.01,{ }^{* * * *} p<.001$. 
Table 1

Summary of Previous Studies that Used Latent Profile Analysis with Spanish-English Bilingual Children

\begin{tabular}{|c|c|c|c|c|c|c|c|}
\hline Reference & $\begin{array}{l}\text { Age } \\
\text { (yrs) }\end{array}$ & $\mathbf{N}$ & $\begin{array}{c}\text { Sample } \\
\text { Characteristics }\end{array}$ & $\begin{array}{l}\text { Domains } \\
\text { Included }\end{array}$ & $\begin{array}{l}\text { Language(s) } \\
\text { examined }\end{array}$ & Measures included & $\begin{array}{l}\text { Number and Description of Profiles } \\
\text { Identified }\end{array}$ \\
\hline $\begin{array}{l}\text { Kapantzoglou } \\
\text { et al. (2015) }\end{array}$ & $5-7$ & 471 & $\begin{array}{l}\text { Predominantly } \\
\text { Spanish-speaking } \\
\text { children }\end{array}$ & $\begin{array}{l}\text { Language, } \\
\text { nonverbal } \\
\text { cognition }\end{array}$ & Spanish & $\begin{array}{l}3 \text { Spanish language sample measures (lexical } \\
\text { D, grammatical errors per terminal unit, } \\
\text { MLUw), } 2 \text { language processing measures } \\
\text { (Spanish nonword repetition and rapid } \\
\text { automatic naming from the SSLIC), and } \\
\text { noncognitive ability measured by the WNV }\end{array}$ & $\begin{array}{l}3 \text { profiles: (a) a low-grammaticality } \\
\text { group; (b) a low phonological working } \\
\text { memory group; and (c) an average group }\end{array}$ \\
\hline $\begin{array}{l}\text { Gonzales et al. } \\
(2016)\end{array}$ & $4-6$ & 252 & $\begin{array}{l}\text { Spanish-dominant } \\
\text { preschool-age } \\
\text { children from low- } \\
\text { income households } \\
\text { enrolled in } \\
\text { preschool dual } \\
\text { language learner } \\
\text { classrooms }\end{array}$ & $\begin{array}{l}\text { Language, } \\
\text { literacy }\end{array}$ & $\begin{array}{l}\text { Spanish, } \\
\text { English }\end{array}$ & $\begin{array}{c}2 \text { code-related measures (Spanish C-PALLS } \\
\text { Letters, Spanish C-PALLS Phonological } \\
\text { Awareness) and } 4 \text { oral language measures } \\
\text { (English preLAS, Spanish preLAS, English } \\
\text { EVT-2, English PPVT-4) }\end{array}$ & $\begin{array}{l}4 \text { profiles: (a) low English language, } \\
\text { average Spanish language, and mixed } \\
\text { Spanish literacy; (b) average English } \\
\text { language, Strengths in Spanish language } \\
\text { and Spanish literacy; (c) mixed English } \\
\text { and Spanish language, low Spanish } \\
\text { literacy skills; and (d) high English } \\
\text { language, average Spanish Language, } \\
\text { and mixed Spanish literacy skills }\end{array}$ \\
\hline $\begin{array}{l}\text { Lonigan et al. } \\
\text { (2017) }\end{array}$ & $3-5$ & 562 & $\begin{array}{l}\text { Spanish-speaking } \\
\text { language- minority } \\
\text { preschoolers } \\
\text { recruited from } \\
\text { Head Start centers }\end{array}$ & $\begin{array}{l}\text { Language, } \\
\text { nonverbal } \\
\text { cognition }\end{array}$ & $\begin{array}{l}\text { Spanish, } \\
\text { English }\end{array}$ & $\begin{array}{l}4 \text { oral language measures including the } \\
\text { Auditory Comprehension } \\
\text { and Expressive Communication subtests of } \\
\text { the English and the Spanish PLS- } 4 \text { and } 1 \\
\text { nonverbal cognitive measure, the pattern } \\
\text { analysis subtest of SB-IV }\end{array}$ & $\begin{array}{c}9 \text { profiles consolidated into } 3 \text { “super } \\
\text { profiles": (a) Spanish-dominant [4 } \\
\text { profiles]; (b) English-dominant [2 } \\
\text { profiles]; and (c) balanced [3 profiles, } \\
\text { including one profile with low skills in } \\
\text { both languages, one with low Spanish } \\
\text { and average English, one with high skills } \\
\text { in both] }\end{array}$ \\
\hline $\begin{array}{l}\text { López \& } \\
\text { Foster (2021) }\end{array}$ & $\begin{array}{l}4.75 \\
- \\
5.75\end{array}$ & 320 & $\begin{array}{l}\text { Spanish-English } \\
\text { dual language } \\
\text { learners recruited } \\
\text { from Head Start } \\
\text { programs }\end{array}$ & $\begin{array}{l}\text { Language, } \\
\text { literacy, } \\
\text { cognition, } \\
\text { mathemati } \\
\quad \text { cs }\end{array}$ & $\begin{array}{l}\text { Spanish, } \\
\text { English }\end{array}$ & W scores from the 9 subtests of WJIII & $\begin{array}{l}4 \text { profiles: (a) average balanced; (b) high } \\
\text { English achievement, low Spanish } \\
\text { achievement; (c) high Spanish } \\
\text { achievement, low English achievement; } \\
\text { and (d) low balanced }\end{array}$ \\
\hline $\begin{array}{l}\text { Halpin et al. } \\
(2021)\end{array}$ & $3-5$ & 161 & $\begin{array}{l}\text { Spanish-English } \\
\text { dual language } \\
\text { learners recruited } \\
\text { from Head Start } \\
\text { programs } \\
\end{array}$ & Language & $\begin{array}{l}\text { Spanish, } \\
\text { English }\end{array}$ & $\begin{array}{l}\text { English and Spanish scores from the } \\
\text { phonology, semantics, and morphology } \\
\text { subtests from BESA }\end{array}$ & $\begin{array}{l}4 \text { profiles: (a) low balanced with a } \\
\text { relative weakness in morphosyntax in } \\
\text { both languages; (b) high balanced; (c) } \\
\text { high Spanish, low English; and (d) low } \\
\text { Spanish, high English }\end{array}$ \\
\hline \multicolumn{8}{|c|}{ 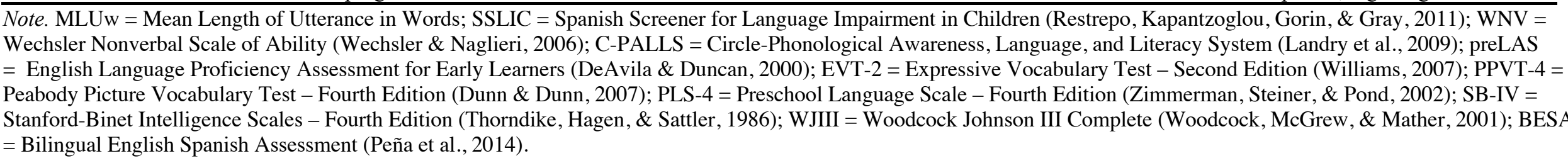 } \\
\hline
\end{tabular}




\section{Table 2}

Correlations and Descriptive Statistics of Variables Used

\begin{tabular}{|c|c|c|c|c|c|c|c|c|}
\hline Variables & Eng SI & Eng MATTR & Eng NSS & Eng WPM & Sp SI & Sp MATTR & Sp NSS & Sp WPM \\
\hline \multicolumn{9}{|l|}{ Eng SI } \\
\hline Eng MATTR & $0.57^{* * *}$ & & & & & & & \\
\hline Eng NSS & $0.54^{* * *}$ & $0.52^{* * *}$ & & & & & & \\
\hline Eng WPM & $0.50^{* * *}$ & $0.52^{* * *}$ & $0.55^{* * *}$ & & & & & \\
\hline Sp SI & $0.35^{* * *}$ & $0.25^{* * *}$ & $0.25^{* * *}$ & $0.28^{* * *}$ & & & & \\
\hline Sp MATTR & $0.20^{* * *}$ & $0.28^{* * *}$ & $0.16^{* * *}$ & $0.13^{* * *}$ & $0.45^{* * *}$ & & & \\
\hline Sp NSS & $0.19^{* * *}$ & $0.17^{* * *}$ & $0.27^{* * *}$ & $0.15^{* * *}$ & $0.36^{* * *}$ & $0.34^{* * *}$ & & \\
\hline Sp WPM & $0.20^{* * *}$ & $0.15^{* * *}$ & $0.18^{* *}$ & $0.42^{* * *}$ & $0.42^{* * *}$ & $0.34^{* * *}$ & $0.38^{* * *}$ & \\
\hline Mean & 1.09 & 0.79 & 19 & 81.61 & 1.19 & 0.84 & 20.96 & 78.72 \\
\hline$S D$ & 0.12 & 0.05 & 5.2 & 27.47 & 0.11 & 0.03 & 4.16 & 23.79 \\
\hline Max & 1.52 & 0.91 & 35 & 161.96 & 1.56 & 0.92 & 35.00 & 149.49 \\
\hline Min & 0.55 & 0.56 & 0 & 19.02 & 1.00 & 0.7 & 6.00 & 10.71 \\
\hline
\end{tabular}

Note. Eng = English; $\mathrm{Sp}=$ Spanish; SI = subordination index; MATTR = moving average type-token ratio; NSS = narrative structure scheme; WPM $=$ words per minute.

${ }^{* * *} p<.01,{ }^{* * *} p<.001$. 
Table 3

Model Fit and Classification Diagnostic Indices for all LPA model estimated

\begin{tabular}{|c|c|c|c|c|c|c|c|c|c|c|c|}
\hline \multirow[b]{2}{*}{$\Sigma_{\mathrm{k}}$} & \multirow{2}{*}{$\begin{array}{c}\text { \# Of } \\
\text { profiles }\end{array}$} & \multirow[b]{2}{*}{$\mathbf{L L}$} & \multicolumn{3}{|c|}{ Information criteria Indices } & \multicolumn{3}{|c|}{ Relative fit indices } & \multicolumn{3}{|c|}{ Overall precision of classification } \\
\hline & & & SABIC & CAIC & AWE & $\begin{array}{l}\text { VLMR- } \\
\text { LRT } \\
\end{array}$ & BLRT & $\mathbf{B F}$ & Entropy & AvePP (\%) & $\begin{array}{c}\text { Min profile } \\
\text { size (\%) } \\
\end{array}$ \\
\hline \multirow{6}{*}{$\begin{array}{l}\text { Class- } \\
\text { invariant, } \\
\text { diagonal } \\
\text { (model A) }\end{array}$} & 1 & -9610.73 & 19278.51 & 19345.32 & 19483.18 & - & - & $1.63 \mathrm{E}-22$ & 1 & 100.00 & $847(100)$ \\
\hline & 2 & -9065.10 & 18219.35 & 18323.74 & 18540.79 & $0.002^{* *}$ & $<.001 * * *$ & 5.33E-92 & 0.75 & 92.24 & $370(44)$ \\
\hline & 3 & -8824.60 & 17770.44 & 17912.41 & 18208.01 & $<.001^{* * *}$ & $<.0011^{* * *}$ & $1.37 \mathrm{E}-34$ & 0.81 & 91.35 & $79(9)$ \\
\hline & 4 & -8716.29 & 17585.91 & 17765.47 & 18139.73 & $0.008^{* *}$ & $<.0011^{* * *}$ & $2.39 \mathrm{E}-27$ & 0.82 & 89.69 & $57(7)$ \\
\hline & 5 & -8624.65 & 17434.74 & 17651.87 & 18104.83 & $0.006^{* *}$ & $<.001^{* * *}$ & $1.08 \mathrm{E}-03$ & 0.81 & 87.23 & $60(7)$ \\
\hline & 6 & -8585.98 & 17389.48 & 17644.20 & 18175.93 & 0.24 & $<.001^{* * *}$ & & 0.75 & 82.33 & $57(7)$ \\
\hline \multirow{6}{*}{$\begin{array}{l}\text { Class- } \\
\text { varying, } \\
\text { diagonal } \\
\text { (model B) }\end{array}$} & 1 & -9610.73 & 19278.51 & 19345.32 & 19483.18 & - & - & $9.42 \mathrm{E}-26$ & 1 & 100.00 & $847(100)$ \\
\hline & 2 & -8947.78 & 18013.24 & 18151.04 & 18437.99 & $<.001^{* * *}$ & $<.001^{* * *}$ & $2.29 \mathrm{E}-77$ & 0.77 & 93.00 & $381(45)$ \\
\hline & 3 & -8714.01 & 17606.31 & 17815.10 & 18250.64 & $0.01^{*}$ & $<.001^{* * *}$ & $1.90 \mathrm{E}-36$ & 0.77 & 74.39 & $139(16)$ \\
\hline & 4 & -8574.46 & 17387.83 & 17667.60 & 18251.75 & $0.04^{*}$ & $<.0011^{* * * *}$ & 4.97E-11 & 0.77 & 86.82 & $106(13)$ \\
\hline & 5 & -8493.43 & 17286.39 & 17637.15 & 18369.91 & 0.23 & $<.001^{* * *}$ & $3.20 \mathrm{E}+04$ & 0.78 & 85 & $70(9)$ \\
\hline & 6 & -8446.49 & 17253.15 & 17674.90 & 18556.33 & 0.37 & $<.001^{* * * *}$ & & 0.74 & 81.58 & $83(10)$ \\
\hline \multirow{6}{*}{$\begin{array}{l}\text { Class- } \\
\text { invariant, } \\
\text { unrestricted } \\
\text { (model C) }\end{array}$} & 1 & -8569.39 & 17295.69 & 17479.42 & 17862.05 & - & - & $1.38 \mathrm{E}-31$ & 1 & 100.00 & 847 (100) \\
\hline & 2 & $\mathbf{- 8 4 6 8 . 0 0}$ & 17124.99 & 17346.30 & 17807.73 & $<.001$ * & $<.001^{* 3 \times 4}$ & $5.40 \mathrm{E}-12$ & 0.94 & 98.00 & $58(7)$ \\
\hline & 3 & -8411.71 & 17044.51 & 17303.41 & 17843.57 & $0.03^{*}$ & $<.0011^{* * *}$ & 8.78E-03 & 0.91 & 96.39 & $48(6)$ \\
\hline & 4 & -8376.64 & 17006.46 & 17302.94 & 17921.93 & $0.03^{*}$ & $<.001^{* * *}$ & 14.22 & 0.83 & 90.93 & $46(5)$ \\
\hline & 5 & -8348.96 & 16983.20 & 17317.25 & 18014.89 & 0.43 & $<.001^{* * *}$ & 344551.90 & 0.85 & 90.59 & $23(3)$ \\
\hline & 6 & -8331.37 & 16980.11 & 17351.75 & 18128.07 & 0.79 & $<.0011^{* * *}$ & & 0.85 & 89.53 & $22(3)$ \\
\hline \multirow{6}{*}{$\begin{array}{l}\text { Class- } \\
\text { varying, } \\
\text { unrestricted } \\
\text { (model D) }\end{array}$} & 1 & -8569.39 & 17295.69 & 17479.42 & 17862.05 & - & - & $1.45 \mathrm{E}-27$ & 1 & 100 & $847(100)$ \\
\hline & 2 & -8355.90 & 17029.18 & 17400.82 & 18177.41 & $<.001^{* * *}$ & $<.001^{* * *}$ & & 0.71 & 92.04 & $169(20)$ \\
\hline & 3 & \multicolumn{10}{|c|}{ Not well-defined: model failed to converge, failed to replicate across random starts, small condition number $=0.10 \mathrm{E}-04$} \\
\hline & 4 & \multicolumn{10}{|c|}{ Not well-defined: model failed to converge, failed to replicate across random starts, small condition number $=0.13 \mathrm{E}-04$} \\
\hline & 5 & \multicolumn{10}{|c|}{ Not well-defined: model failed to converge, failed to replicate across random starts, small condition number $=0.10 \mathrm{E}-09$} \\
\hline & $\theta$ & \multicolumn{10}{|c|}{ Not well-defined: model failed to converge, failed to replicate across random starts, small condition number $=0.10 \mathrm{E}-09$} \\
\hline
\end{tabular}

Note. $\mathrm{LL}=\log$ likelihood value; SABIC $=$ sample-adjusted Bayesian information criterion; CAIC = Consistent Akaike's Information Criterion; AWE = Approximate Weight of Evidence Criterion; VLMR-LRT = Vuong-Lo-Mendell-Rubin Likelihood Ratio Test; BLRT = Bootstrap Likelihood Ratio Test; BF = Bayes Factor; AvePP $=$ Average posterior probabilities. Bold values represent the values that correspond to the best or preferred fit index within each $\boldsymbol{\Sigma}_{\mathbf{k}}$. For example, for LL, models with a LL value larger than the value associated with the benchmark model were bolded; for BIC, CAIC, AWE, models with the smallest value among each set were bolded. Bolded boxes correspond to the best fit index within all estimated models. Dashed box highlights the minimum-goodness-of-fit benchmark model. ${ }^{*} p<.05,{ }^{* *} p$ $<.01, \stackrel{* * * *}{p} p<.001$. 
Table 4

Mean and SD for English and Spanish Oral Language Raw Scores for Latent Profiles 1-4 Identified in the Final LPA Solution (Model C4)

\begin{tabular}{|c|c|c|c|c|}
\hline Measures & $\begin{array}{c}\begin{array}{c}\text { Profile 1 } \\
\mathbf{N}=\mathbf{6 5 5}, \mathbf{7 7 . 3 3 \%}\end{array} \\
M(S D)\end{array}$ & $\begin{array}{c}\begin{array}{c}\text { Profile } \mathbf{2} \\
\mathbf{N}=\mathbf{5 8}, \mathbf{6 . 8 5} \%\end{array} \\
M(S D)\end{array}$ & $\begin{array}{c}\begin{array}{c}\text { Profile 3 } \\
\mathbf{N}=\mathbf{4 6}, \mathbf{5 . 4 3} \%\end{array} \\
M(S D)\end{array}$ & $\begin{array}{c}\text { Profile } \mathbf{4} \\
\mathbf{N = 5 2 , 6 . 1 8 \%} \\
M(S D)\end{array}$ \\
\hline \multicolumn{5}{|l|}{ English measures } \\
\hline Eng SI & $1.09(0.11)$ & $0.11(0.95)$ & $1.1(0.11)$ & $1.2(0.1)$ \\
\hline Eng MATTR & $0.8(0.04)$ & $0.04(0.66)$ & $0.8(0.04)$ & $0.82(0.03)$ \\
\hline Eng NSS & $19.37(4.94)$ & $4.94(12.29)$ & $18.7(5.13)$ & $20.84(4.61)$ \\
\hline Eng WPM & $82.23(26.12)$ & $26.12(46.42)$ & $85(21.74)$ & $98.4(25.38)$ \\
\hline \multicolumn{5}{|l|}{ Spanish measures } \\
\hline Span SI & $1.18(0.08)$ & $1.16(0.09)$ & $1.1(0.07)$ & $1.38(0.07)$ \\
\hline Span MATTR & $0.84(0.03)$ & $0.83(0.03)$ & $0.76(0.02)$ & $0.86(0.02)$ \\
\hline Span NSS & $21.13(3.87)$ & $19.53(3.74)$ & $16.13(4.41)$ & $23.15(4.25)$ \\
\hline Span WPM & $80.81(23.39)$ & $70.86(19.68)$ & $51.15(16.06)$ & $82.82(22.51)$ \\
\hline
\end{tabular}

